\title{
Mineralogy and noble gas isotopes of micrometeorites collected from Antarctic snow
}

Ryuji Okazaki ${ }^{*}$, Takaaki Noguchi², Shin-ichi Tsujimoto ${ }^{3}$, Yu Tobimatsu $^{4}$, Tomoki Nakamura ${ }^{5}$, Mitsuru Ebihara ${ }^{6}$, Shoichi Itoh ${ }^{7}$, Hiroko Nagahara ${ }^{8}$, Shogo Tachibana ${ }^{9}$, Kentaro Terada ${ }^{10}$ and Hikaru Yabuta ${ }^{10}$

\begin{abstract}
We have investigated seven micrometeorites (MMs) from Antarctic snow collected in 2003 and 2010 by means of electron microscopy, X-ray diffraction, micro-Raman spectroscopy, transmission electron microscopy (TEM) observation, and noble-gas isotope analysis. Isotopic ratios of $\mathrm{He}$ and $\mathrm{Ne}$ indicate that the noble gases in these MMs are mostly of solar wind (SW). Based on the release patterns of SW ${ }^{4} \mathrm{He}$, which should reflect the degree of heating during atmospheric entry, the seven MMs were classified into three types including two least heated, three moderately heated, and two severely heated MMs. The heating degrees are well correlated to their mineralogical features determined by TEM observation. One of the least heated MMs is composed of phyllosilicates, whereas the other consists of anhydrous minerals within which solar flare tracks were observed. The two severely heated MMs show clear evidence of atmospheric heating such as partial melt of the uppermost surface layer in one and abundant patches of dendritic magnetite and Si-rich glass within an olivine grain in the other. It is noteworthy that a moderately heated MM composed of a single crystal of olivine has a ${ }^{3} \mathrm{He} /{ }^{4} \mathrm{He}$ ratio of $8.44 \times 10^{-4}$, which is higher than the SW value of $4.64 \times 10^{-4}$, but does not show a cosmogenic ${ }^{21} \mathrm{Ne}$ signature such as ${ }^{20} \mathrm{Ne} /{ }^{21} \mathrm{Ne} /{ }^{22} \mathrm{Ne}=12.83$ / $0.0284 / 1$. The isotopic compositions of $\mathrm{He}$ and $\mathrm{Ne}$ in this sample cannot be explained by mixing of a galactic cosmic ray (GCR)-produced component and SW gases. The high ${ }^{3} \mathrm{He} /{ }^{4} \mathrm{He}$ ratio without cosmogenic ${ }^{21} \mathrm{Ne}$ signature likely indicates the presence of a ${ }^{3} \mathrm{He}$-enriched component derived from solar energetic particles.
\end{abstract}

Keywords: Antarctic micrometeorites; Noble gas; Transmission electron microscopy; Atmospheric entry heating; Solar energetic particles

\section{Background}

Our understanding of the evolution history of our early solar system materials stands on studies of extraterrestrial materials originating from asteroids and comets. Asteroidal materials occurring as meteorites have been studied in detail. In particular, those recovered from the asteroid Itokawa by the Hayabusa spacecraft have been subjected to comprehensive studies (e.g., Nakamura et al. 2011; Noguchi et al. 2011, 2014a, 2014b; Nagao et al. 2011; Tsuchiyama et al. 2011; Yurimoto et al. 2011; Nakamura et al. 2012; Harries and Langenhorst 2014; Keller and Berger 2014; Langenhorst et al. 2014; Mikouchi et al. 2014; Thompson et al. 2014; Takeda et al. 2015). In contrast, it is difficult to obtain samples

\footnotetext{
* Correspondence: okazaki.ryuji.703@m.kyushu-u.ac.jp

${ }^{1}$ Department of Earth and Planetary Sciences, Faculty of Sciences, Kyushu

University, 33, Hakozaki, Higashi-ku, Fukuoka 812-8581, Japan

Full list of author information is available at the end of the article
}

identified to be cometary in origin, with the exception of direct sampling by the Stardust mission that returned the dust samples from the short-period comet 81P/Wild 2 (Zolensky et al. 2006). A possible approach for investigating cometary samples is the study of cosmic dust. This method is likely the best and easiest technique because cosmic dust is accreted to the Earth in large quantities of $\sim 40,000$ tons annually (e.g., Love and Brownlee 1993; Taylor et al. 1998; Yada et al. 2004) and can be collected in Antarctica and Greenland as micrometeorites (MMs) and in the stratosphere as interplanetary dust particles (IDPs). Although IDPs are suggested to be mainly of cometary origin (e.g., Joswiak et al. 2005), the abundance ratios, or relative proportions, of asteroidal and cometary particles in MMs are not well known and thus need to be clarified.

Previous studies have focused on distinguishing between asteroidal and cometary particles based on their 
overall properties such as the combination of mineralogy, chemistry, isotopic compositions, and orbital parameters inferred from the degree of heating during atmospheric entry (e.g., Sandford and Bradley 1989; Love and Brownlee 1991, 1994; Nier and Schlutter 1992, 1993). Thermal alteration during atmospheric entry causes various effects on IDPs and MMs including a loss of volatile elements (Kehm et al. 2002) and noble gases (e.g., Nier and Schlutter 1992, 1993; Füri et al. 2013), decomposition and formation of secondary minerals (e.g., Greshake et al. 1998; Toppani et al. 2001; Nozaki et al. 2006) such as magnetite shells or envelopes (Keller et al. 1992; Kurat et al. 1994), and modification of infrared spectra (Sandford and Bradley 1989). The release pattern of noble gases is one of the most sensitive parameters in atmospheric entry heating because solar wind $(\mathrm{SW})$ noble gases are implanted onto the surfaces of IDPs and MMs in interplanetary space. A comparison of noble gas release patterns and mineralogical characteristics enable discussion of the time in which the dust particles were heated, whether in the parent body, in space, or during atmospheric entry, and in addition the manner of heating revealed by peak temperature, heating duration, and oxygen fugacity.

However, combined research on noble gas analysis and mineralogical investigation has rarely been performed despite its usefulness because of the small size of samples, which creates difficulties in their handling. In addition, the resin used to fix samples could cause a false increase in the background levels of a noble-gas mass spectrometer as reactive organic interference and can create an atmospheric gas trap. As exceptions, Osawa et al. (2003a) and Bajo et al. (2011) performed scanning electron microscopy (SEM)/energy dispersive spectrometry (EDS) and synchrotron radiation X-ray diffraction (SR-XRD) analyses to characterize the appearance, bulk chemical composition, and bulk mineralogy of the particles prior to conducting noble gas measurements. Okazaki and Nakamura (2006) conducted SEM, electron probe microanalysis (EPMA), and secondary ion mass spectrometry (SIMS) analyses on the cross sections of individual Antarctic MMs in addition to observations of their appearances and bulk chemistry measurements by SEM/EDS prior to the noble-gas analysis. In this study, we used an acetone-soluble resin and changed the configuration of the focused ion beam (FIB) sectioning, which enabled us to perform multidiscipline analyses of MMs, particularly transmission electron microscopy (TEM) observation and noble-gas analysis. Here, we present the results of a combined study of the mineralogy and noble gas isotopes of MMs collected from Antarctic snow.

\section{Methods}

\section{Detection of micrometeorites and SEM observation}

The surface snow samplings in Antarctica were conducted by the National Institute of Polar Research (NIPR) in the 42nd and 51st Japan Antarctic Research Expedition (JARE) in 2003 and 2010, respectively. Antarctic snow samples JARE-42 and JARE-51, respectively about 100 and $300 \mathrm{~kg}$, were collected near Dome Fuji Station, Antarctica, and were transferred to Japan in a frozen state. The snow was melted at $20{ }^{\circ} \mathrm{C}$ and was percolated with membrane filters of $0.8 \mu \mathrm{m}$ in pore diameter at Ibaraki University. Recovered MMs were mounted on Pt sheets for the SEM observation at Ibaraki University. About 500 MMs were identified among the fine-grained residual particles based on their morphologies and EDS spectra. We regarded the MMs as small particles enriched in $\mathrm{Mg}, \mathrm{Si}$, and $\mathrm{Fe}$ with lesser amounts of $\mathrm{Al}$ and $\mathrm{S}$. The appearances and interior textures of the MMs were observed by using an FIB-SEM (JEOL JIB-4501) with an acceleration voltage of $15 \mathrm{kV}$. Bulk chemical compositions were determined by EDS (JEOL JED-2300 equipped with the FIB-SEM) calibrated with Orgueil CI chondrite as the laboratory standard. To detect the mineralogy and degrees of heating, we selected MMs with apparent sizes of approximately $50 \mu \mathrm{m}$ in diameter because particles in such a size range could not have incurred melting but could have experienced various degrees of heating during atmospheric entry, according to the calculation by Love and Brownlee (1991, 1994). At first, degrees of heating were determined by the appearance of MMs observed by FIB-SEM (e.g., Kurat et al. 1994). Seven MMs were ultimately selected for TEM and noble gas studies (Table 1). Table 1 summarizes sample IDs, petrographic classification, apparent sizes, constituent minerals determined by SR-XRD and micro-Raman analyses, and the degree of heating during atmospheric entry deduced on the basis of ${ }^{4} \mathrm{He}$ release patterns, which is subsequently discussed in the "Noble gas compositions and release patterns" section.

\section{SR-XRD analysis}

Powder diffraction patterns of the individual MM samples were determined by SR-XRD at the beam line 3A at the Photon Factory Institute of Material Science, HighEnergy Accelerator Research Organization, Tsukuba, Japan. Each sample was mounted on a thin glass fiber of $5 \mu \mathrm{m}$ in diameter by using acetone-soluble resin and was exposed to synchrotron X-rays in a Gandolfi camera that was evacuated to $\sim 7 \mathrm{~Pa}$ to decrease the scattering of $\mathrm{X}$ rays by the atmosphere. The X-rays were monochromated to $2.1655 \pm 0.0009 \AA$ and were concentrated by a short-gap undulator. The X-ray diffraction pattern was recorded on imaging plates read by an IP reader (Typhoon FLA7000) with a resolution of diffraction angle of $0.025^{\circ}$.

\section{FIB microsectioning and TEM observation}

Following the SR-XRD analysis, the samples were mounted on Mo strips using acetone-soluble resin and were cut off 
Table 1 Sample list with the degree of atmospheric entry heating, apparent sizes, and mineralogical features

\begin{tabular}{|c|c|c|c|c|c|}
\hline \multirow{2}{*}{$\begin{array}{l}\text { Sample } \\
\text { ID }\end{array}$} & \multirow{2}{*}{$\begin{array}{l}\text { Degree of } \\
\text { atmospheric entry }\end{array}$} & \multirow{2}{*}{$\begin{array}{l}\text { Apparent } \\
\text { size }(\mu \mathrm{m})\end{array}$} & \multirow{2}{*}{$\begin{array}{l}\text { Petrographic } \\
\text { characteristics }\end{array}$} & \multicolumn{2}{|l|}{ Identified minerals } \\
\hline & & & & SR-XRD & Micro-Raman \\
\hline D03IB067 & Least heated & 43 & Polycrystalline (anhydrous) & $\mathrm{Ol}, \mathrm{LPx}, \mathrm{Kam}, \mathrm{Po}, \mathrm{Mt}$ & $\mathrm{Ol}$ \\
\hline D03IB068 & Least heated & 45 & Polycrystalline (hydrous) & Ol, Mt, Sap, Serp & Ol \\
\hline D10IB020 & Moderately heated & 50 & Chondrule-like & $\mathrm{Ol}, \mathrm{HPx}$ & $\mathrm{Ol}, \mathrm{HPx}$ \\
\hline D10IB049 & Moderately heated & 43 & Coarse-grained & OI, LPx, Po, Mt & Ol, Low-Ca cpx \\
\hline D10IB130 & Moderately heated & 60 & Coarse-grained & $\mathrm{Ol}$ & Ol \\
\hline D03IB057 & Severely heated & 33 & Chondrule-like & Ol, LPx, Kam, Po, Pl, Mt & Low-Ca cpx, Ol, Chr \\
\hline D10IB170 & Severely heated & 50 & Coarse-grained & $\mathrm{Ol}, \mathrm{Mt}$ & $\mathrm{Ol}, \mathrm{Mt}$ \\
\hline
\end{tabular}

Degrees of atmospheric entry heating were inferred from the release patterns of solar wind ${ }^{4} \mathrm{He}$

Ol olivine, LPx low-Ca pyroxene, Kam kamacite, Po pyrrhotite, Mt magnetite, Sap saponite, Serp serpentine, HPx high-Ca pyroxene, $P$ I plagioclase, low-Ca cpx low-Ca clinopyroxene, $\mathrm{Chr}$ chromite

parallel to the wafers as a 100-nm-thick section by using the FIB-SEM (JEOL JIB-4501) at Ibaraki University for TEM. Different from normal FIB sample preparation procedures, the FIB sections were prepared parallel to the surface of substrate Mo plates, upon which each of the MMs was attached, for further micro-Raman and EPMA analyses. The proportion consumed by the FIB cutting was small, corresponding to only 5-10 and 10-20\% of each particle in volume and in surface area, respectively, assuming that a portion $6 \mu \mathrm{m}$ thick from the top surface of a spherical body was consumed. TEM observation was performed by using JEOL JEM-2100 TEM equipped with Oxford INCA EDS at Ibaraki University and FEI Tecnai $20 \mathrm{~F}$ TEM equipped with EDAX Exact Genesis EDS at Kyushu University.

\section{Micro-Raman spectroscopy and EPMA analysis}

Because the surface of the remaining sample after FIB sample preparation was parallel to the Mo substrate, we were able to use Raman spectroscopy to identify the minerals on the surface by using a micro-Raman spectrometer (JASCO NRS-3100) at Ibaraki University. The excitation laser has a wavelength of $532 \mathrm{~nm}$ and a beam diameter of $2 \mu \mathrm{m}$. The exposure time on the samples and the power of the excitation laser were $80 \mathrm{~s}(40 \mathrm{~s} \times 2)$ and $10 \mathrm{~mW}$, respectively. The peak position of the Raman spectra was calibrated by using the strongest Raman shift peak of metallic $\mathrm{Si}$ at $520 \mathrm{~cm}^{-1}$.

After the micro-Raman analysis, the MMs were coated with carbon to determine their bulk and mineral chemistries. The chemical analyses were performed with a JEOL JXA-8530 F FE-EPMA at JEOL Co. The acceleration voltage and the probe current were $15 \mathrm{kV}$ and $9 \mathrm{nA}$, respectively. ZAF-oxide correction was applied to calculate the chemical compositions of the minerals.

\section{Noble gas analysis}

Each MM sample mounted on a silicon wafer was removed by using acetone and was then washed separately by acetone, ethanol, and pure water. After weighing with an ultra-microbalance (Sartorius MSU-2.7S) at Kyushu University, individual MMs were wrapped with Al foil $10 \mu \mathrm{m}$ in thickness. To remove adsorbed atmospheric gases, the samples were heated at $150{ }^{\circ} \mathrm{C}$ for $24 \mathrm{~h}$ in a sample holder connected to a gas purification line of the mass spectrometer. The heating temperature was determined considering that MMs and IDPs had been heated at a minimum of several hundred ${ }^{\circ} \mathrm{C}$ for several seconds (e.g., Love and Brownlee 1994). In addition, our samples consisted mainly of olivine with only small amounts of glass and quartz, in which $\mathrm{He}$ can diffuse faster (e.g., Kurz and Jenkins 1981) than that in olivine, from which He can hardly escape during the baking (e.g., Trull and Kurz 1993). This was supported by our noble gas results. For example, one MM consisting of hydrous minerals (Table 1), D03IB068, has a higher ${ }^{4} \mathrm{He} /{ }^{20} \mathrm{Ne}$ ratio and lower ${ }^{4} \mathrm{He}$ release temperature than that of the other $\mathrm{MMs}$, suggesting that preferential release of $\mathrm{He}$ by baking did not occur even in the least heated MM. Hence, the baking procedure did not affect the noble gas compositions of all of the MMs studied.

Each sample was dropped into a Mo crucible and was heated stepwise at 400,650 , and $1800{ }^{\circ} \mathrm{C}$ to extract noble gases in a "pot-pie" furnace designed for noble gas analysis of microgram samples. Isotopic ratios and amounts of noble gases were determined with the modified Micromass MM5400 noble-gas mass spectrometer at Kyushu University. Sensitivities and mass fractionation factors of the spectrometer were determined by measuring the known amounts of atmospheric gas and a He-standard gas with a ${ }^{3} \mathrm{He} /{ }^{4} \mathrm{He}$ ratio of $1.71 \times 10^{-4}$. Repeated measurements of standard gases confirmed the stabilities of sensitivities of the mass spectrometer to be $<10 \%$. The blank gas abundances were as follows: ${ }^{4} \mathrm{He}=5 \times 10^{-12},{ }^{20} \mathrm{Ne}=5-$ $7 \times 10^{-13},{ }^{36} \mathrm{Ar}=1-2 \times 10^{-12},{ }^{40} \mathrm{Ar}=2-4 \times 10^{-10},{ }^{84} \mathrm{Kr}=1-$ $3 \times 10^{-14},{ }^{132} \mathrm{Xe}=2-6 \times 10^{-15} \mathrm{~cm}^{3}$ standard temperature and pressure (STP). The abundances of ${ }^{20} \mathrm{Ne}$ and ${ }^{22} \mathrm{Ne}$ were corrected for divalent interferences of ${ }^{40} \mathrm{Ar}^{++}$and ${ }^{12} \mathrm{C}^{16} \mathrm{O}_{2}^{++}$, 
which were around $5 \times 10^{-14}$ and $1 \times 10^{-14} \mathrm{~cm}^{3}$ STP during sample measurements, respectively.

\section{Results}

\section{Noble gas compositions and release patterns}

Figure 1 shows the release profiles of ${ }^{4} \mathrm{He}$ extracted from the MMs by using the stepped-heating method. The intervals of extraction temperatures are 400, 650, and $1800{ }^{\circ} \mathrm{C}$ after $150{ }^{\circ} \mathrm{C}$ preheating to remove the adsorbed atmosphere. As inferred from their isotopic ratios of $\mathrm{He}$ and $\mathrm{Ne}$ (Table 2), the major noble gas component in the MMs studied is SW gas. The bulk concentrations of ${ }^{36} \mathrm{Ar}$ in most of the MMs studied are relatively higher than those reported for unmelted MMs (e.g., Osawa and Nagao 2002, Osawa et al. 2003a).

Two MMs, D03IB067 and D03IB068, released 2 and $4 \%$ of bulk ${ }^{4} \mathrm{He}$, respectively, at $400{ }^{\circ} \mathrm{C}$. Three MMs, D03IB020, D10IB049, and D10IB130, released 7-26\% of ${ }^{4} \mathrm{He}$ at $650{ }^{\circ} \mathrm{C}$ but negligibly small amounts of ${ }^{4} \mathrm{He}$ $(<0.1 \%)$ at $400{ }^{\circ} \mathrm{C}$ (Table 2). Only at $1800{ }^{\circ} \mathrm{C}$, detectable amounts of ${ }^{4} \mathrm{He}$ were released from D03IB057 and D10IB170. Based on these release profiles, we classified seven MMs into three types: least heated, moderately heated, and severely heated MMs (Table 1). The bulk concentrations of ${ }^{4} \mathrm{He}$ are not completely correlated with the classification based on their release profiles. D03IB067, the least heated MM, contains the largest amount of ${ }^{4} \mathrm{He}$ among the seven MMs, whereas another least heated MM, D03IB068, contains a smaller amount of ${ }^{4} \mathrm{He}$ than that in the two moderately heated MMs, D10IB020 and D10IB130, as shown in Table 2 and in Fig. 2. This nonconcordance can be attributed to various SW exposure duration, and the small sample sizes because only two MMs, D10IB020 and D10IB049, had weights of $>0.1 \mu \mathrm{g}$ measurable with the electric ultramicrobalance. We assumed weights of $0.1 \mu \mathrm{g}$ for the other samples (Table 2) based on their apparent sizes $(\sim 40 \mu \mathrm{m}$; Table 1$)$ and density $\left(\sim 3 \mathrm{~g} / \mathrm{cm}^{3}\right)$. Assuming $50 \%$ uncertainties for the $0.1-\mu$ g sample weights, the ${ }^{4} \mathrm{He}$ concentrations of three MMs, D03IB068, D10IB020, and D10IB049, will overlap with each other within their uncertainties. The solar ${ }^{4} \mathrm{He}$ abundances in the $\mathrm{MM}$ samples could also be affected the amount of original surface remaining in the samples after FIB cutting because the solar gases are surface-correlated. When the gas abundances are normalized by the surface area remaining after the FIB cutting calculated by assuming spherical objects (the "FIB microsectioning and TEM observation" section and Table 2), the ${ }^{4} \mathrm{He}$ concentrations are $3.9 \mathrm{~cm}^{3} \mathrm{STP} / \mathrm{cm}^{2}, 5.8 \mathrm{~cm}^{3} \mathrm{STP} / \mathrm{cm}^{2}$, and $4.8 \times$ $10^{-6} \mathrm{~cm}^{3} \mathrm{STP} / \mathrm{cm}^{2}$ for D03IB068, D10IB020, and D10IB130, respectively. The surface area used in the calculation also included uncertainties of probably at several tens of percent. Hence, it is not easy to discuss the degrees of heating based on the absolute concentrations of noble gases; the release patterns are the most useful and important indicators of the noble gas characteristics of the MMs.

Figure 2 shows the relationship between the ${ }^{4} \mathrm{He}$ concentrations and the elemental ratios of ${ }^{4} \mathrm{He} /{ }^{20} \mathrm{Ne}$. The elemental ratios of ${ }^{4} \mathrm{He} /{ }^{20} \mathrm{Ne}$ in IDPs, MMs (our data and unmelted MMs reported in Osawa and Nagao 2002, Osawa et al. 2003a), and cosmic spherules are lower than those of SW (Heber et al. 2009) and implantationfractionated SW (IFSW), previously interpreted as solar energetic particles (SEPs), represented in lunar ilmenite

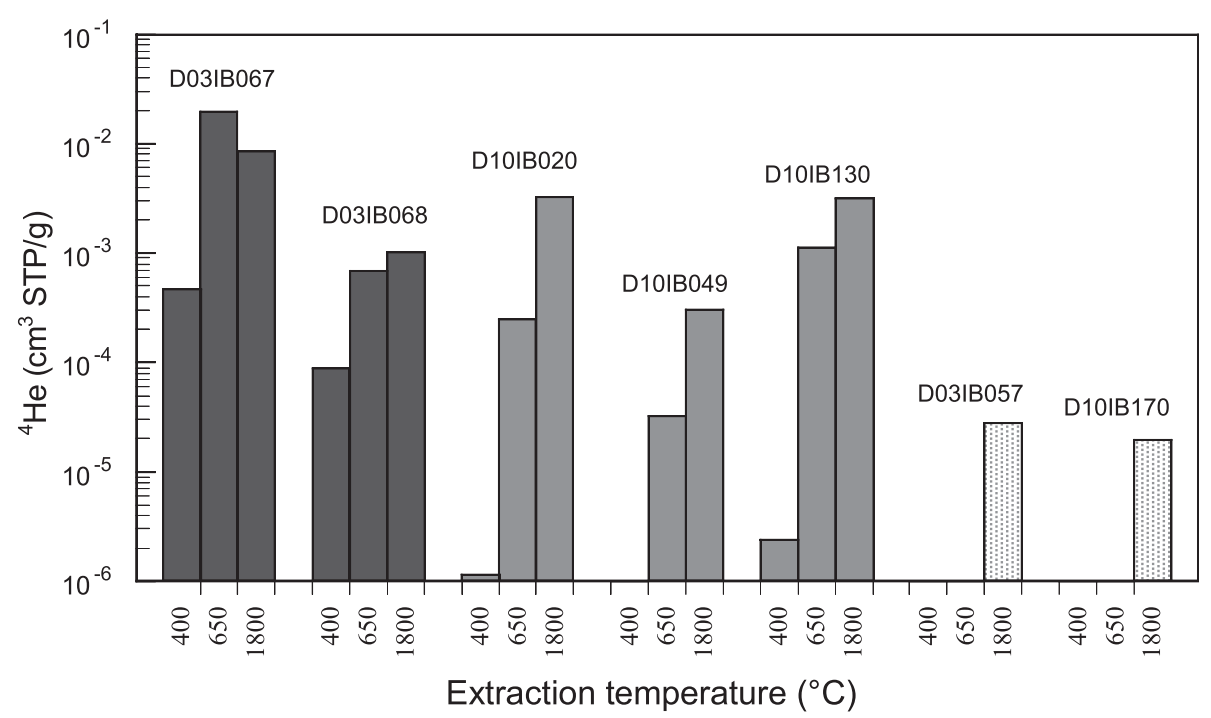

Fig. 1 Release profiles of ${ }^{4} \mathrm{He}$ from each micrometeorite determined by stepped-heating noble gas analyses. Three different release patterns, least heated (D03IB067, D03IB068), moderately heated (D101B020, D10IB049, D10IB130), and severely heated (D03IB057, D10IB170) are shown 
Table 2 Concentrations and isotopic ratios of micrometeorites collected from Antarctic snow

\begin{tabular}{|c|c|c|c|c|c|c|c|c|c|c|c|}
\hline Sample ID (weight) & $\begin{array}{l}\text { Temperature } \\
\left({ }^{\circ} \mathrm{C}\right)\end{array}$ & ${ }^{4} \mathrm{He}$ & ${ }^{3} \mathrm{He} /{ }^{4} \mathrm{He}$ & ${ }^{22} \mathrm{Ne}$ & ${ }^{20} \mathrm{Ne} /{ }^{22} \mathrm{Ne}$ & ${ }^{21} \mathrm{Ne} /{ }^{22} \mathrm{Ne}$ & ${ }^{36} \mathrm{Ar}$ & ${ }^{38} \mathrm{Ar}{ }^{136} \mathrm{Ar}$ & ${ }^{40} \mathrm{Ar} /{ }^{36} \mathrm{Ar}$ & ${ }^{84} \mathrm{Kr}$ & 132 \\
\hline D03IB067 & 400 & 470 & $0.00023 \pm 0.00012$ & 0.100 & $13 \pm 11$ & ND & 4.53 & $0.184 \pm 0.062$ & $215 \pm 44$ & 0.024 & 0.010 \\
\hline \multirow[t]{2}{*}{$(0.1 \mu \mathrm{g})$} & 650 & 19,700 & $0.000240 \pm 0.000017$ & 7.18 & $11.77 \pm 0.40$ & $0.0258 \pm 0.0094$ & 13.0 & $0.204 \pm 0.044$ & $125 \pm 40$ & 0.122 & ND \\
\hline & 1800 & 8470 & $0.000227 \pm 0.000022$ & 20.0 & $11.45 \pm 0.33$ & $0.0307 \pm 0.0087$ & 39.9 & $0.201 \pm 0.013$ & $214.5 \pm 9.4$ & 0.395 & 0.048 \\
\hline Total & & 28,640 & $0.000236 \pm 0.000014$ & 27.3 & $11.54 \pm 0.27$ & $0.0294 \pm 0.0068$ & 57.4 & $0.200 \pm 0.014$ & $194 \pm 12$ & 0.541 & 0.058 \\
\hline D03IB068 & 400 & 88.0 & ND & ND & ND & ND & 6.38 & $0.193 \pm 0.066$ & $223 \pm 31$ & 0.098 & 0.019 \\
\hline \multirow[t]{2}{*}{$(0.1 \mu \mathrm{g})$} & 650 & 691 & $0.00040 \pm 0.00015$ & 3.56 & $12.33 \pm 1.18$ & $0.028 \pm 0.012$ & 8.85 & $0.221 \pm 0.064$ & $216 \pm 40$ & 0.089 & 0.007 \\
\hline & 1800 & 1020 & $0.000450 \pm 0.000060$ & 3.93 & $11.78 \pm 0.79$ & $0.040 \pm 0.020$ & 33.9 & $0.187 \pm 0.011$ & $227.4 \pm 9.7$ & 0.400 & 0.059 \\
\hline Total & & 1799 & $0.000429 \pm 0.000068$ & 7.49 & $12.04 \pm 0.70$ & $0.035 \pm 0.012$ & 49.1 & $0.194 \pm 0.016$ & $225 \pm 11$ & 0.587 & 0.085 \\
\hline $10 \mid B 020$ & 400 & 1.16 & ND & ND & ND & ND & 2.51 & $0.229 \pm 0.084$ & $195 \pm 58$ & 0.006 & 0.005 \\
\hline \multirow[t]{2}{*}{$(0.2 \mu \mathrm{g})$} & 650 & 247 & $0.00026 \pm 0.00016$ & 0.257 & $9.9 \pm 4.0$ & ND & 3.85 & $0.186 \pm 0.054$ & $153 \pm 60$ & 0.031 & ND \\
\hline & 1800 & 3270 & $0.000249 \pm 0.000015$ & 9.49 & $11.41 \pm 0.37$ & $0.0255 \pm 0.0058$ & 41.3 & $0.1926 \pm 0.0056$ & $236.3 \pm 5.9$ & 0.800 & 0.111 \\
\hline Total & & 3518 & $0.000250 \pm 0.000018$ & 9.75 & $11.37 \pm 0.37$ & $0.0255 \pm 0.0058$ & 47.7 & $0.1940 \pm 0.0079$ & $227.4 \pm 7.6$ & 0.836 & 0.116 \\
\hline D10IB049 & 400 & ND & ND & ND & ND & ND & 1.60 & $0.154 \pm 0.071$ & $294 \pm 43$ & 0.028 & 0.009 \\
\hline \multirow[t]{2}{*}{$(0.3 \mu \mathrm{g})$} & 650 & 32.2 & ND & 0.279 & $14.2 \pm 2.8$ & ND & 3.15 & $0.173 \pm 0.059$ & $150 \pm 47$ & 0.042 & 0.002 \\
\hline & 1800 & 303 & $0.000385 \pm 0.000077$ & 6.83 & $11.63 \pm 0.53$ & $0.0250 \pm 0.0031$ & 21.1 & $0.190 \pm 0.010$ & $188.0 \pm 7.6$ & 0.276 & 0.038 \\
\hline Total & & 335 & $0.000385 \pm 0.000077$ & 7.11 & $11.73 \pm 0.52$ & $0.0250 \pm 0.0031$ & 25.9 & $0.185 \pm 0.012$ & $189.8 \pm 8.9$ & 0.345 & 0.050 \\
\hline D10IB130 & 400 & 2.40 & ND & ND & ND & ND & 6.19 & $0.173 \pm 0.051$ & $242 \pm 28$ & 0.023 & 0.022 \\
\hline \multirow[t]{2}{*}{$(0.1 \mu \mathrm{g})$} & 650 & 1120 & $0.00068 \pm 0.00014$ & 5.30 & $12.79 \pm 0.71$ & $0.0236 \pm 0.0081$ & 12.5 & $0.190 \pm 0.027$ & $93 \pm 49$ & 0.064 & ND \\
\hline & 1800 & 3180 & $0.000900 \pm 0.000035$ & 34.5 & $12.84 \pm 0.32$ & $0.0291 \pm 0.0036$ & 57.4 & $0.187 \pm 0.013$ & $140 \pm 12$ & 0.322 & 0.063 \\
\hline Total & & 4302 & $0.000844 \pm 0.000046$ & 39.8 & $12.83 \pm 0.29$ & $0.0284 \pm 0.0033$ & 76.1 & $0.186 \pm 0.011$ & $141 \pm 12$ & 0.409 & 0.084 \\
\hline D03|B057 & 400 & ND & ND & ND & ND & ND & 5.45 & $0.16 \pm 0.11$ & $238 \pm 39$ & 0.017 & 0.014 \\
\hline \multirow[t]{2}{*}{$(0.1 \mu \mathrm{g})$} & 650 & ND & ND & ND & ND & ND & 4.84 & $0.22 \pm 0.10$ & $137 \pm 101$ & 0.109 & 0.006 \\
\hline & 1800 & 28.0 & ND & 2.06 & $10.14 \pm 0.95$ & $0.029 \pm 0.023$ & 41.1 & $0.182 \pm 0.015$ & $266.3 \pm 8.8$ & 0.807 & 0.118 \\
\hline Total & & 28.0 & & 2.06 & $10.14 \pm 0.95$ & $0.029 \pm 0.023$ & 51.4 & $0.184 \pm 0.019$ & $251 \pm 13$ & 0.933 & 0.138 \\
\hline D10IB170 & 400 & ND & ND & ND & ND & ND & 5.34 & $0.202 \pm 0.073$ & $236 \pm 36$ & 0.088 & 0.018 \\
\hline \multirow[t]{2}{*}{$(0.1 \mu \mathrm{g})$} & 650 & ND & ND & 0.245 & $10.4 \pm 7.2$ & ND & 6.86 & $0.218 \pm 0.057$ & $190 \pm 50$ & 0.098 & 0.012 \\
\hline & 1800 & 19.5 & ND & 4.53 & $10.88 \pm 0.77$ & $0.025 \pm 0.014$ & 24.2 & $0.196 \pm 0.016$ & $241 \pm 11$ & 0.248 & 0.041 \\
\hline Total & & 19.5 & & 4.78 & $10.85 \pm 0.81$ & $0.025 \pm 0.014$ & 36.4 & $0.201 \pm 0.018$ & $231 \pm 13$ & 0.434 & 0.071 \\
\hline
\end{tabular}

Concentrations are shown in $10^{-6} \mathrm{~cm}^{3}$ standard temperature and pressure (STP)/g. Uncertainties for gas abundance ( $\mathrm{cm}^{3}$ STP) were calculated to be $\sim 10 \%$ considering the stability of sensitivities and variation of background levels of the mass spectrometer $N D$ values not determined due to low gas abundances

I71501/5 (Benkert et al. 1993; the "Formation of secondary magnetite and diffusive loss of He during atmospheric entry heating" section). However, the ratios were higher than that of the terrestrial atmosphere (complied by Ozima and Podosek 2002). It is noteworthy that a positive correlation is present between ${ }^{4} \mathrm{He}$ concentrations and ${ }^{4} \mathrm{He} /{ }^{20} \mathrm{Ne}$ ratios of the MMs in this study, as reported in previous studies (e.g., Nier and Schlutter 1990; Nagao et al. 2011). The severely heated MMs studied here and cosmic spherules (Osawa et al. 2003b) have lower ${ }^{4} \mathrm{He}$ concentrations and ${ }^{4} \mathrm{He} /{ }^{20} \mathrm{Ne}$ ratios than those in the least heated MMs and IDPs (Nier and Schlutter 1990), which tend to have higher values (Fig. 2). The ${ }^{4} \mathrm{He} /{ }^{20} \mathrm{Ne}$ ratio of one severely heated MM, D10IB170, is almost identical to the atmospheric value (Fig. 2), although the $\mathrm{Ne}$ and $\mathrm{Ar}$ isotopic ratios in the $1800{ }^{\circ} \mathrm{C}$ fraction are different from the atmospheric values (Table 2). Another severely heated MM, D03IB057, also has a ${ }^{4} \mathrm{He} /{ }^{20} \mathrm{Ne}$ ratio similar to the atmospheric value (Fig. 2), although the ${ }^{40} \mathrm{Ar} /{ }^{36} \mathrm{Ar}$ ratios are distinct from the terrestrial value (Table 2).

The bulk isotopic ratios of $\mathrm{He}$ and $\mathrm{Ne}$ for the MMs are shown in Fig. 3. No MMs shows clear ${ }^{21} \mathrm{Ne}$ excesses when cosmogenic $\mathrm{Ne}$ exists beyond the trapped $\mathrm{Ne}$ (Fig. 3a). Considering the analytical uncertainties of isotopic ratios of $\mathrm{Ne}$ (Table 2), it is reasonable to interpret that $\mathrm{Ne}$ in all MMs except for the two severely heated samples are mixtures of SW and IFSW. The ${ }^{20} \mathrm{Ne} /{ }^{22} \mathrm{Ne}$ ratios for the severely heated MMs are lower than those of IFSW due to contribution from the atmospheric Ne, and the isotopic fractionation during atmospheric 


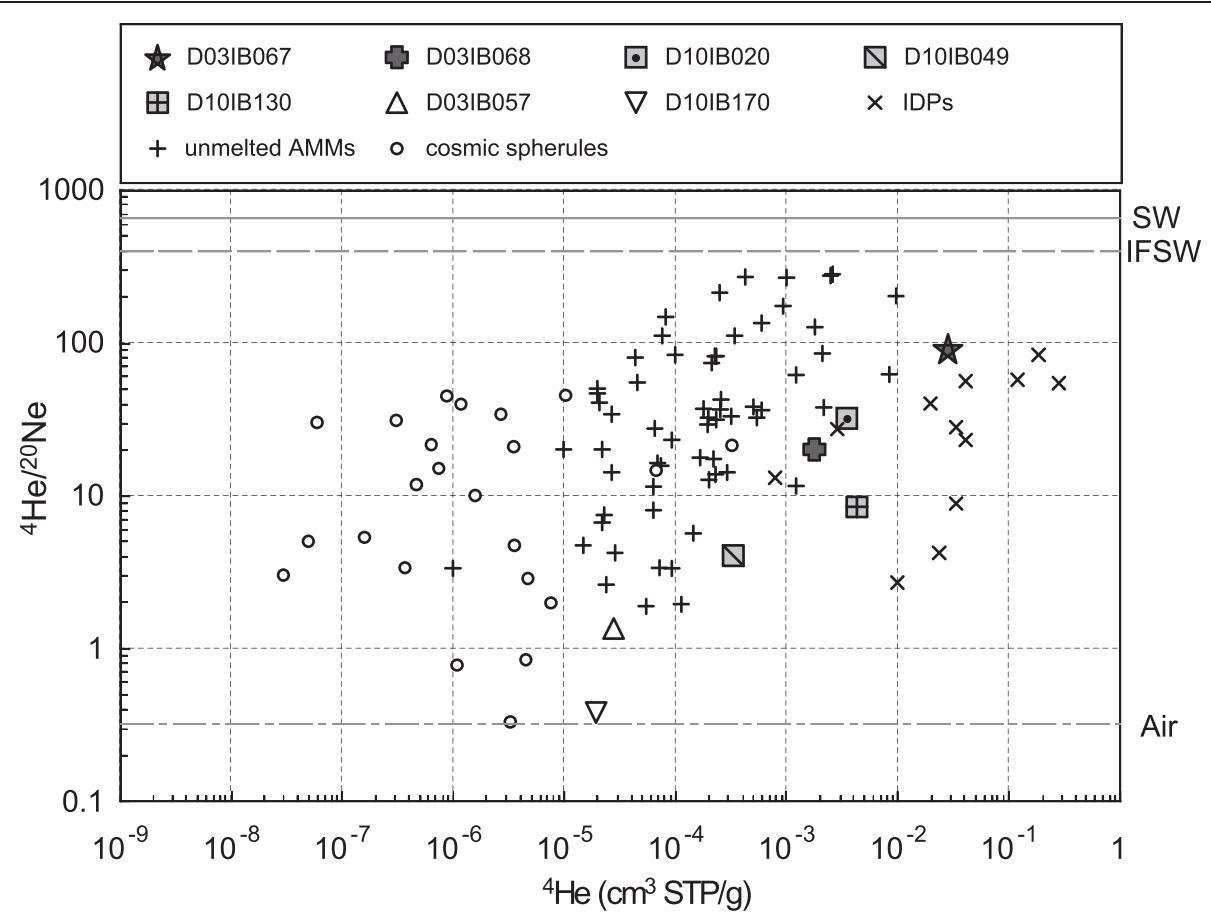

Fig. 2 Concentrations of ${ }^{4} \mathrm{He}$ and elemental ratios of ${ }^{4} \mathrm{He} /{ }^{20} \mathrm{Ne}$ for micrometeorites (MMs) collected from Antarctic snow. Data for interplanetary dust particles (IDPs; Nier and Schlutter 1990), unmelted Antarctic MMs (Osawa and Nagao 2002, Osawa et al. 2003a), and cosmic spherules (Osawa et al. 2003b) are also shown for comparison. Elemental ratios of ${ }^{4} \mathrm{He} /{ }^{20} \mathrm{Ne}$ for the present-day solar wind (SW; Heber et al. 2009), the implantation-fractionated SW (IFSW; Benkert et al. 1993), and the terrestrial atmosphere (Air; Ozima and Podosek 2002) are also shown

heating is considerably higher than that in the other MMs (Fig. 3a).

Figure $3 \mathrm{~b}$ shows ${ }^{3} \mathrm{He} /{ }^{4} \mathrm{He}$ versus ${ }^{20} \mathrm{Ne} /{ }^{22} \mathrm{Ne}$ ratios for the least and moderately heated MMs; the ${ }^{3} \mathrm{He} /{ }^{4} \mathrm{He}$ ratios could not be determined for the severely heated MMs (Table 2). The mixing lines shown in Fig. $3 \mathrm{~b}$ were calculated by assuming the following values: $\left({ }^{3} \mathrm{He} /{ }^{4} \mathrm{He}\right)_{\text {Air }}=1.40 \times 10^{-6}$, $\left({ }^{20} \mathrm{Ne} /{ }^{22} \mathrm{Ne}\right)_{\text {Air }}=9.8$, and $\left({ }^{4} \mathrm{He} /{ }^{20} \mathrm{Ne}\right)_{\text {Air }}=0.319$ for the terrestrial atmosphere (compiled by Ozima and Podosek 2002); $\left({ }^{3} \mathrm{He} /{ }^{4} \mathrm{He}\right)_{\mathrm{SW}}=4.57 \times 10^{-4}, \quad\left({ }^{20} \mathrm{Ne} /{ }^{22} \mathrm{Ne}\right)_{\mathrm{SW}}=13.78$, and $\left({ }^{4} \mathrm{He} /{ }^{20} \mathrm{Ne}\right)_{\mathrm{SW}}=656$ for the present SW (Heber et al. 2009); $\left({ }^{3} \mathrm{He} /{ }^{4} \mathrm{He}\right)_{\mathrm{IFSW}}=2.29 \times 10^{-4},\left({ }^{20} \mathrm{Ne} /{ }^{22} \mathrm{Ne}\right)_{\mathrm{IFSW}}=11.2$, and $\left({ }^{4} \mathrm{He} /{ }^{20} \mathrm{Ne}\right)_{\text {IFSW }}=390$ for the IFSW in lunar ilmenite grains (Benkert et al. 1993); $\left({ }^{3} \mathrm{He} /{ }^{4} \mathrm{He}\right)_{\text {Itokawa }}=3.52 \times 10^{-4}$, $\left({ }^{20} \mathrm{Ne} /{ }^{22} \mathrm{Ne}\right)_{\text {Itokawa }}=13.6$, and $\left({ }^{4} \mathrm{He} /{ }^{20} \mathrm{Ne}\right)_{\text {Itokawa }}=110$ for an Itokawa particle RA-QD02-0065 (Nagao et al. 2011); and $\left({ }^{3} \mathrm{He} /{ }^{4} \mathrm{He}\right)_{\mathrm{GCR}}=0.30, \quad\left({ }^{20} \mathrm{Ne} /{ }^{22} \mathrm{Ne}\right)_{\mathrm{GCR}}=0.80, \quad$ and $\quad\left({ }^{4} \mathrm{He} /\right.$ $\left.{ }^{20} \mathrm{Ne}\right)_{\mathrm{GCR}}=27$ for a galactic cosmic ray (GCR)-produced component calculated for a spherical L-chondrite body with a $10-\mathrm{cm}$ radius irradiated at a $0-1 \mathrm{~cm}$ depth (Leya and Masarik 2009). The $\mathrm{He}$ and $\mathrm{Ne}$ in all of the MMs studied are mixtures of normal SW and IFSW. Moreover, variable but minor contributions of the GCR-produced component are noted in D03IB068 and D10IB049 but not in D10IB130. The origin of the excess ${ }^{3} \mathrm{He}$ in D10IB130 is discussed in the "Formation of secondary magnetite and diffusive loss of He during atmospheric entry heating" section.

\section{Surface appearance and bulk mineralogy}

As shown in Fig. 4, all of the MMs are relatively angular (Fig. 4a-e and g) except for the heavily heated D03IB057, which is less angular and has a smooth surface (Fig. 4f). The least heated MMs, D03IB067 and D03IB068, both have an irregular and rough surface (Fig. 4a, b). The surface of D10IB170, the other heavily heated MM, has a reticulated and netted texture (Fig. 4g). Two moderately heated MMs, D10IB020 and D10IB049, have irregular surfaces (Fig. 4c, d). Fine-grained material is visible on the surface of D10IB049 (Fig. 4d). The other moderately heated MM, D10IB130, has a smooth surface (Fig. 4e).

\section{Interior texture, mineral chemistry, and TEM observations}

After identification and observation of the samples, cross sections were prepared from each MM by FIB and were observed by using FE-SEM. Three types of the textural features were visible in the cross sections of the MMs studied here including fine-grained polycrystalline in anhydrous D03IB067 and hydrous D03IB068, coarse-grained crystalline in D10IB049, D10IB130, and D10IB170, and chondrule-like cryptocrystalline in D10IB020 and D03IB057 (Table 1). Low-Ca pyroxenes in D10IB049 and D03IB057 were identified as low-Ca clinopyroxene (low-Ca cpx) based on the micro-Raman spectrum (Huang et al. 2000). Chromite was identified in D03IB057 by using micro-Raman spectroscopy (Wang et al. 2004). Some minerals identified by 

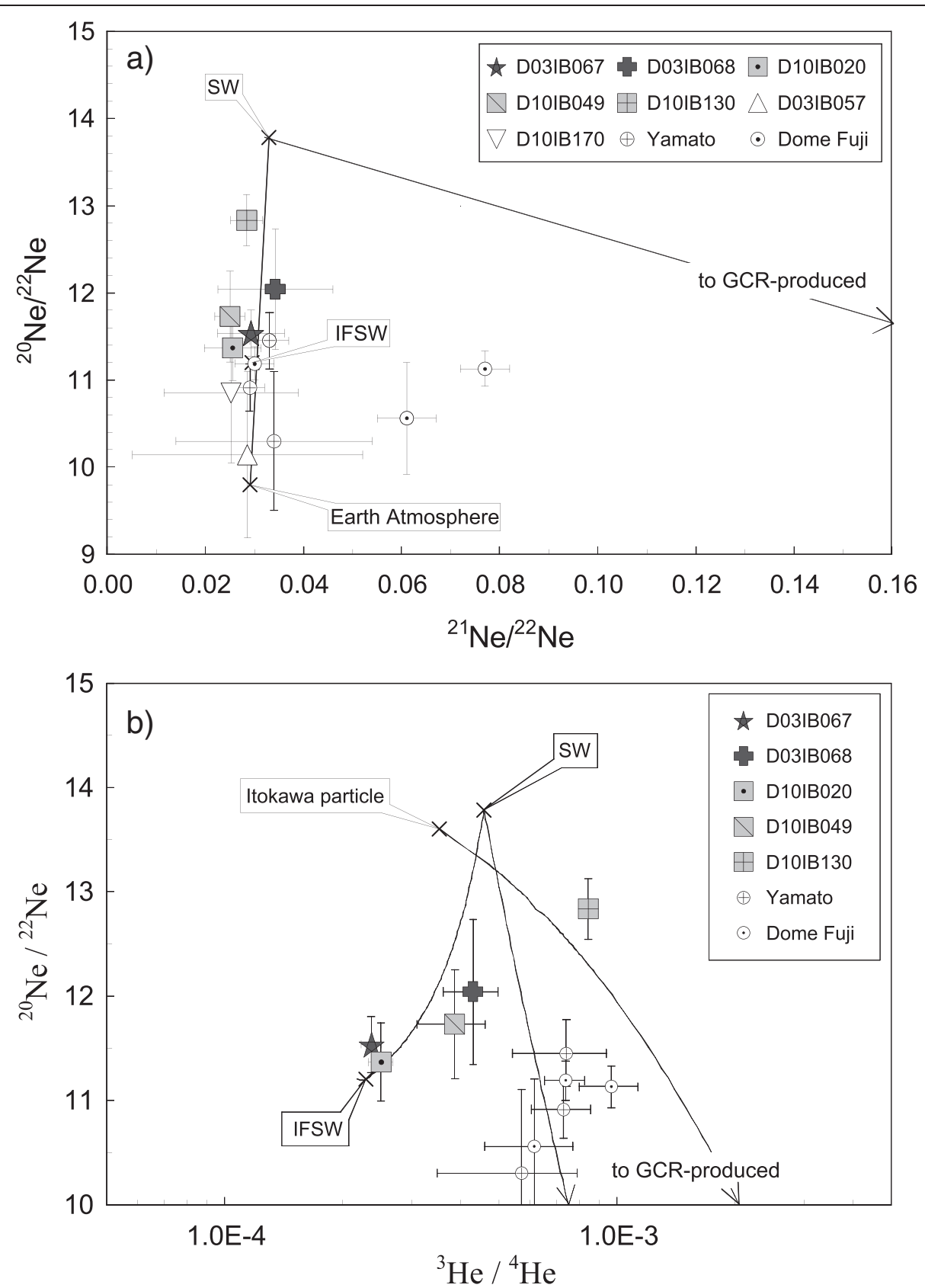

Fig. 3 Bulk isotopic compositions of micrometeorites (MMs) studied. Isotopic ratios of $\mathbf{a}{ }^{21} \mathrm{Ne} /{ }^{22} \mathrm{Ne}$ and $\mathbf{b}{ }^{3} \mathrm{He} /{ }^{4} \mathrm{He}$ are plotted against ${ }^{20} \mathrm{Ne} /{ }^{22} \mathrm{Ne}$ ratios. The tie lines are two-component mixing lines calculated by using the isotopic and elemental compositions for the present-day solar wind (SW; Heber et al. 2009), implantation-fractionated SW (IFSW; Benkert et al. 1993), terrestrial atmosphere (Air; Ozima and Podosek 2002), Itokawa particles (Nagao et al. 2011), and a galactic cosmic ray (GCR)-produced component (Leya and Masarik 2009). MMs collected at the Yamato Mountains and near Dome Fuji Station (Osawa and Nagao 2002, Osawa et al. 2003a) showing ${ }^{3} \mathrm{He} /{ }^{4} \mathrm{He}$ ratios $>5 \times 10^{-4}$ are plotted for comparison, respectively

SR-XRD could not be identified by Raman spectroscopy because they are Raman inactive or were not found in the cross sections. Hereafter, we will describe the mineralogical features as compared with the degrees of heating during atmospheric entry inferred from the release patterns of noble gases (the "Noble gas compositions and release patterns" section).

\section{Least heated MMs}

D03IB067 consists of fine-grained anhydrous minerals, olivine, low-Ca pyroxene, and opaque phases (Fig. 5a), as identified by SR-XRD. Numerous solar flare (SF) tracks were observed in the olivine and pyroxene grains of this MM, as indicated in Fig. 6a by arrows. 


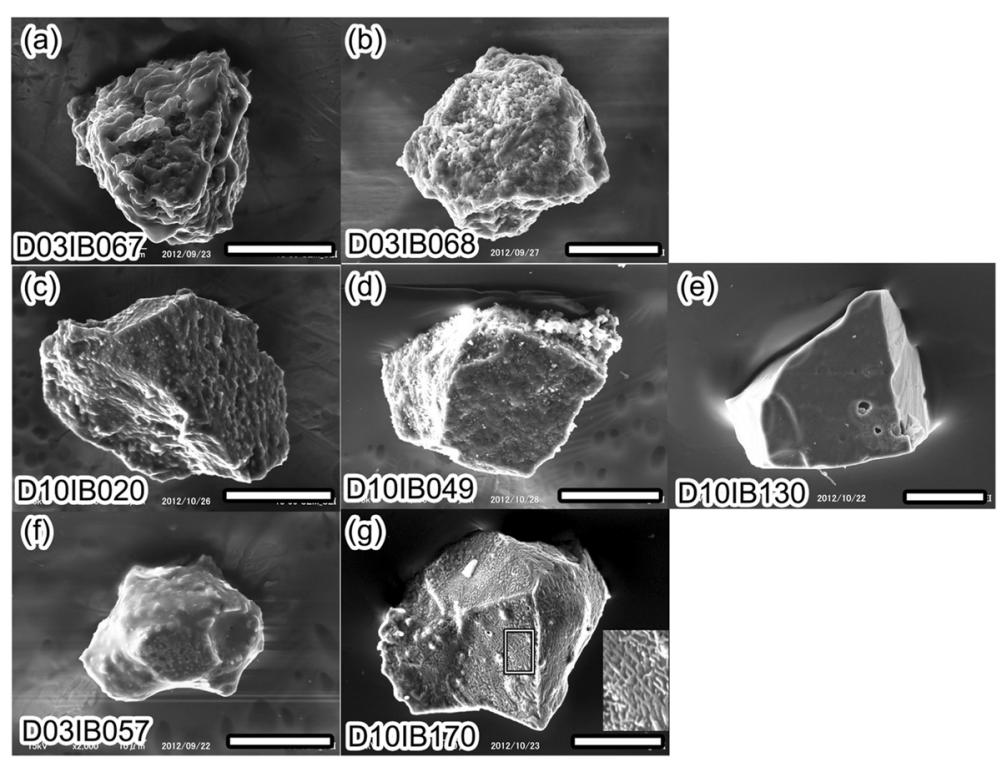

Fig. 4 a-g Secondary electron images of the micrometeorites (MMs) investigated in this study arranged according to the He release patterns (Fig. 1). The scale bars indicate $20 \mu \mathrm{m}$

The other least heated MM, D03IB068, contains a small numbers of pores in the cross section (Fig. 5b). The enlarged image of the boxed area in Fig. 5b reveals that some portions are composed of bundles of fibrous phyllosilicates (Fig. 5c). Figure 7a shows chemical compositions of the phyllosilicates in this MM, which indicates that three of our analyzed points have compositions between serpentine and saponite and plot along a line with an $\mathrm{Mg} /(\mathrm{Mg}+\mathrm{Fe})$ atomic ratio of $\sim 0.85$ (Fig. 7a). Moreover, the compositions of the three analyzed points are similar to those of coarse-grained phyllosilicates in Orgueil (Tomeoka and Buseck 1988) and in a hydrated IDP that was slightly shifted toward Si-rich due to contamination of silicon oil (Keller et al. 1992). The phyllosilicates in this MM exhibit different spacing in the basal lattice fringes, 0.90 to $1.17 \mathrm{~nm}$ suggestive of saponite (Fig. 6b) and $0.71 \mathrm{~nm}$ suggestive of serpentine (Fig. 6c). This conclusion is consistent with the phyllosilicates identified by SR-XRD (Table 1).

\section{Moderately heated MMs}

D10IB020 shows a fern-like texture similar to those observed in cryptocrystalline chondrules and is composed mainly of olivine and Si-rich glass, which are shown with bright and dark contrasts in Fig. 8a. Figure 9a is a highangle annular diffraction-scanning transmission electron microscope (HAADF-STEM) image of D10IB020 and indicates that the fern-like area contains kamacite $(\mathrm{Km})$ and chromite (Chr) as accessary phases. The microRaman spectroscopy shows that patchy areas (indicated by dotted ellipsoids in Fig. 8a) are composed of high-Ca pyroxene, olivine, and glass.
D10IB049 consists mainly of low-Ca cpx. Other mineral phases identified with the SR-XRD are observed as fine-grained materials attached onto its original surface (indicated by arrows in Fig. 8b). Although this MM is classified to be coarse-grained based on FE-SEM observation (Table 1), it is an aggregate of fine-grained lowCa cpx of $<2 \mu \mathrm{m}$ in size (Fig. 9b).

D10IB130 is a MM consisting of a single olivine crystal with uniform chemical composition (Fig. 7b). Arrays of $\sim 1-\mu \mathrm{m}$-sized holes and some discrete $3-5-\mu \mathrm{m}$ holes are visible in this MM (Fig. 8c). Dendrites of magnetite are visible at the original surface in abundance (Fig. 9c, d) just below the tungsten deposition (W depo. in Fig. 9c) and are developed on a large scale (typically $\sim 100 \mathrm{~nm}$ ) at the original surface and along cracks (Fig. 9d) and are embedded in glass (Fig. 9e). Each of dendritic magnetite grains appears to be $\sim 10-20 \mathrm{~nm}$ in size (Fig. 9e).

\section{Severely heated MMs}

D03IB057 appears to have been partly melted and has a two-layered structure in which a porphyritic low-Ca pyroxene core grain is surrounded by ferroan $\left(\mathrm{Fa}_{22-27}\right.$; Fig. 7b) olivine and glass (Fig. 10a). Among all MMs studied, the olivine composition in this sample is the most variable (Fig. 7b). The core low-Ca pyroxene is twinned low-Ca cpx $\left(\mathrm{Wo}_{2.0} \mathrm{En}_{82.4}\right)$. Magnetite is found in the boundary between the low-Ca cpx core and the olivine-glass rim and on the surface of the olivine-glass rim (Fig. 10a). Chrome-bearing magnetite identified by the Raman spectroscopy (Table 1) is associated with dendritic overgrowth of magnetite (Fig. 11a). A kamacite inclusion is included only in the low-Ca cpx core. 


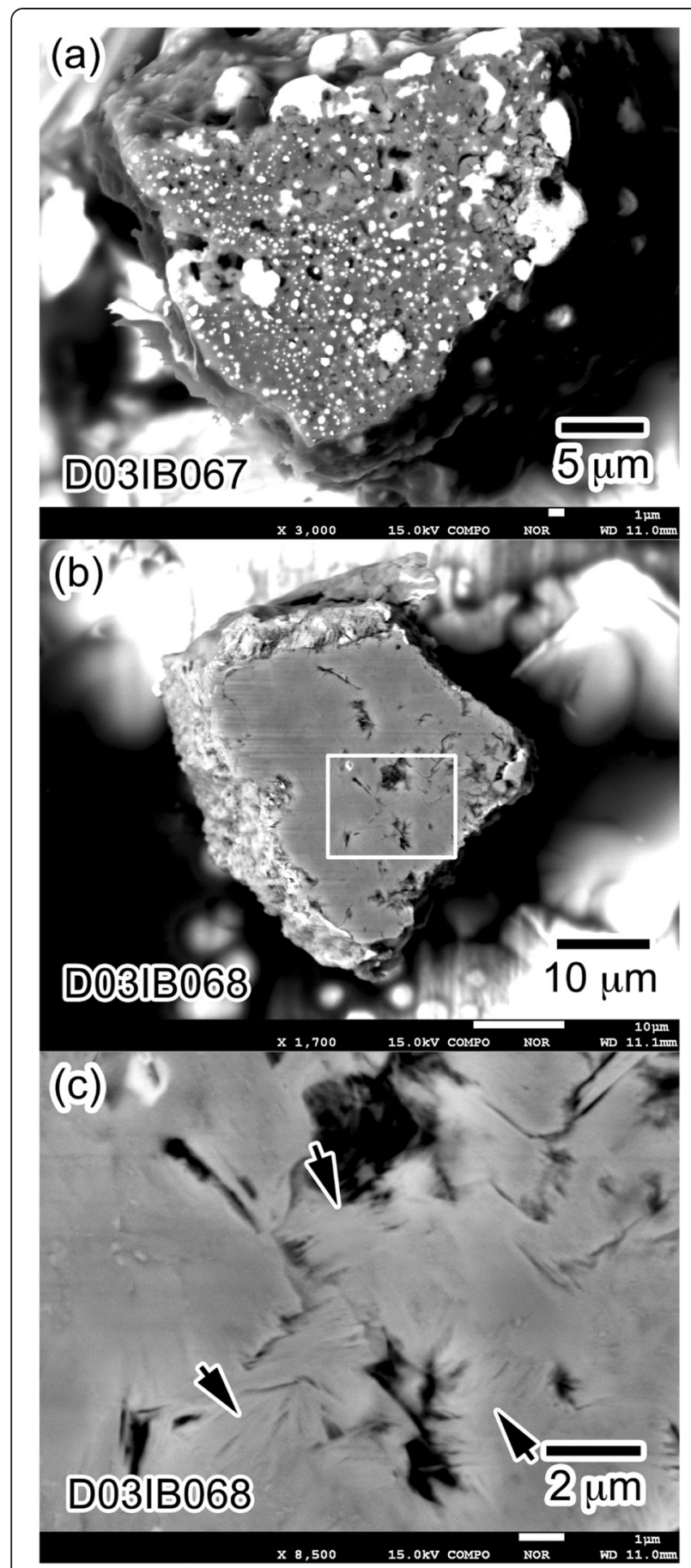

Fig. 5 Back scattered electron (BSE) images of the cross sections of the least heated micrometeorites (MMs) investigated in this study. a D03IB067 is a fine-grained MM. b D03IB068 is a hydrated MM. c An enlarged image of the boxed area in (b). The compact matrix is composed of bundles of fibrous phyllosilicates. Fibrous morphology can be clearly observed in the areas indicated by arrows
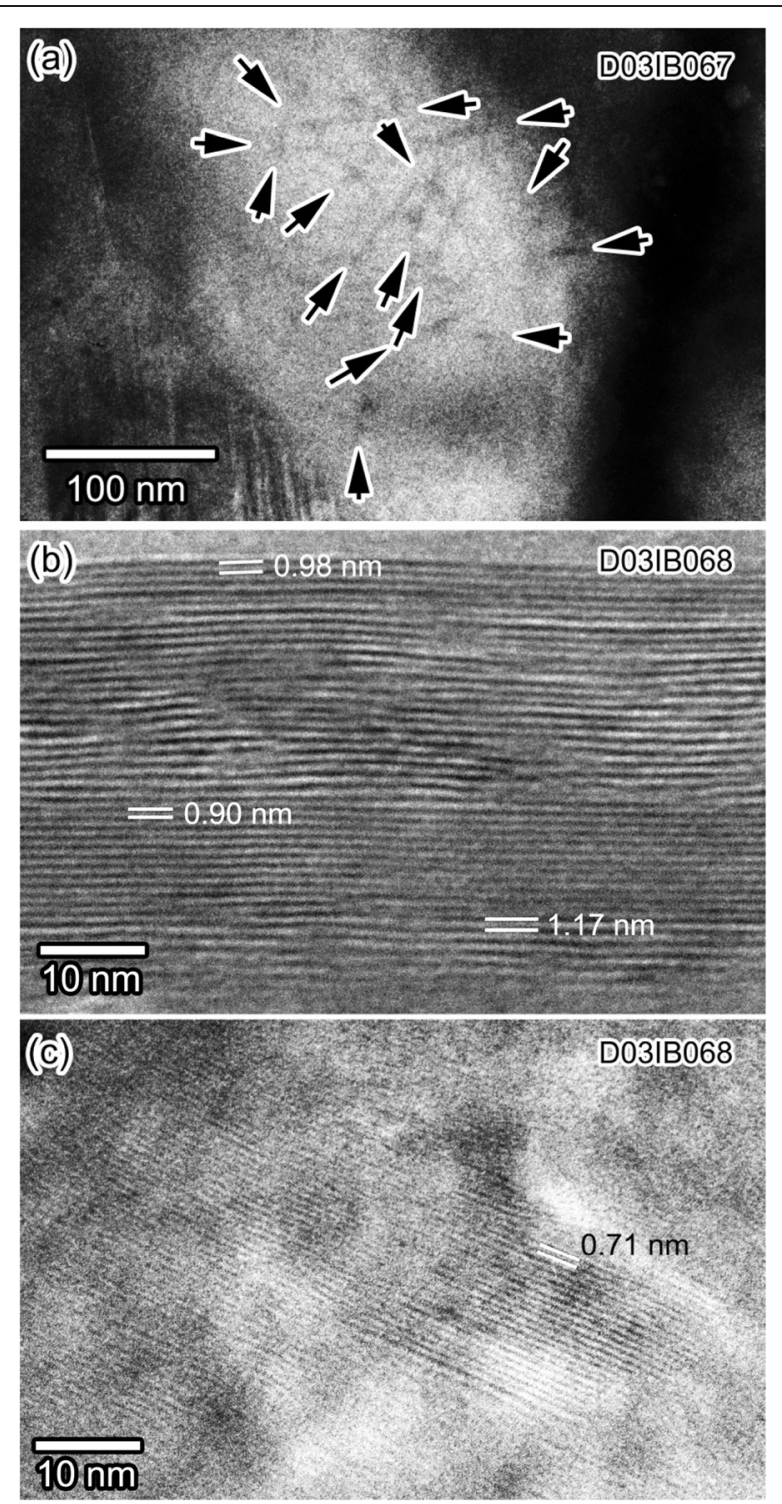

Fig. 6 Transmission electron microscopy (TEM) images of the least heated micrometeorites (MMs). a Dark field image of solar flare tracks (indicated by arrows) in olivine in D03IB067. Lattice fringes of b saponite and c serpentine in D03IB068

D10IB170 consists mainly of olivine containing numerous small magnetite inclusions, and glass patches occur within the interior (Figs. 10b and 11b); these results are highly similar to those reported by $\mathrm{Wu}$ and Kohlstedt (1988). The olivine in this MM is more ferroan $\left(\mathrm{Fa}_{28-31}\right)$ than that in D10IB057 (Fig. 7b).

\section{Discussion}

Peak temperature during atmospheric entry heating

Numerous studies conducted on the condition of heating during atmospheric entry have cited several factors such as particle size, entry angle, and entry speed (e.g., 


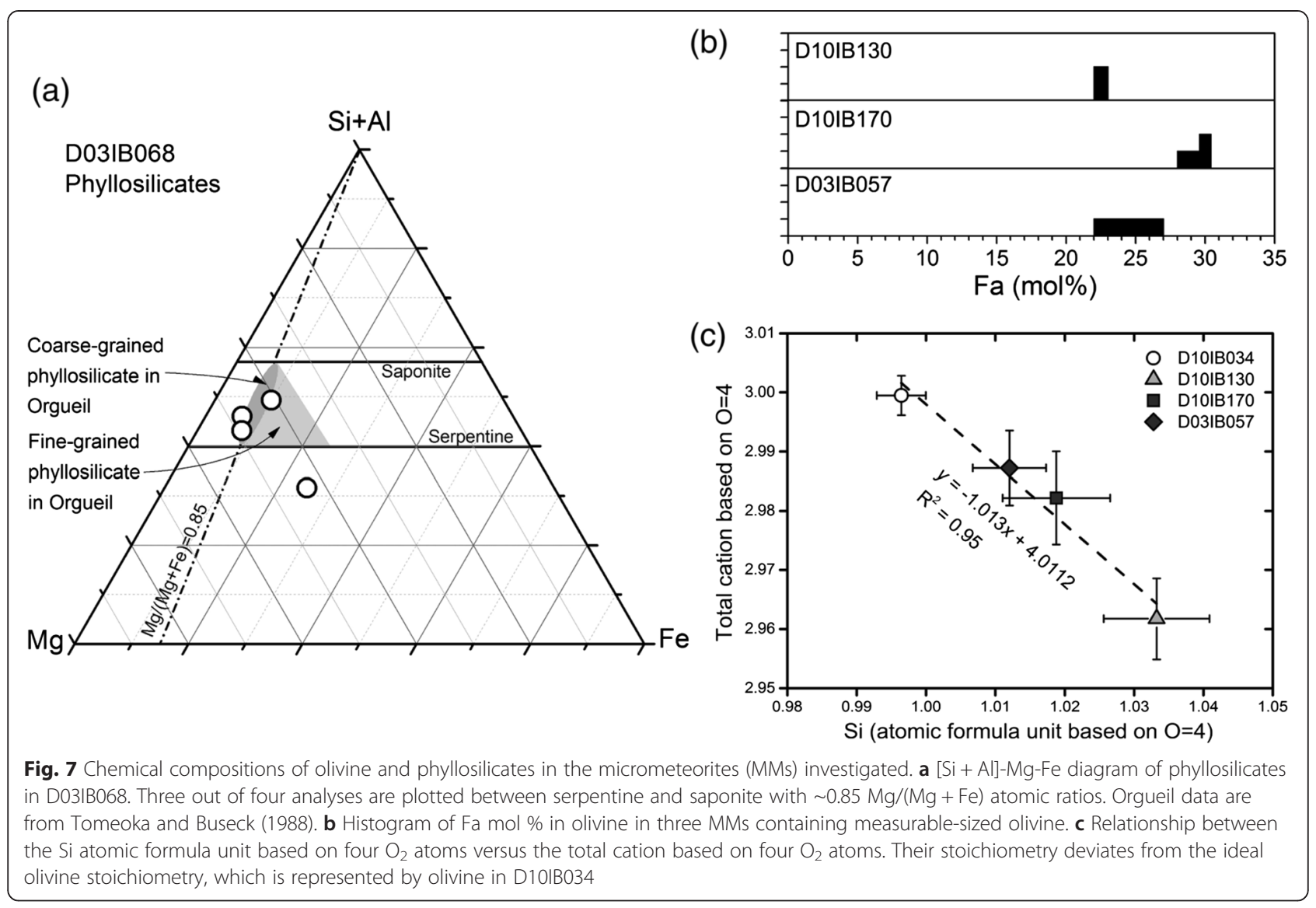

Love and Brownlee 1991, 1994). As discussed in previous studies (e.g., Nier and Schlutter 1992, 1993), the peak temperature can be estimated from the $50 \%$ release temperature of ${ }^{4} \mathrm{He}$ during stepped-heating extractions. In this study, we performed only three steps of extraction to obtain precise isotopic ratios, particularly of $\mathrm{Ne}$; hence, the peak temperature cannot be determined from only the release profiles in most cases. Here, we estimate the peak temperature for the MMs studied based on the results of our noble-gas and mineralogical analyses, taking the results of previous numerical calculations and simulation experiments into consideration as well.

\section{Least heated MMs}

For the least heated MMs, the release patterns of ${ }^{4} \mathrm{He}$ (Fig. 1) indicate peak temperatures of 400 to $650{ }^{\circ} \mathrm{C}$ because $\sim 50 \%$ of ${ }^{4} \mathrm{He}$ is released by $650{ }^{\circ} \mathrm{C}$, including 71 and $43 \%$ for D03IB067 and D03IB068, respectively, as calculated from Table 2 (Nier and Schlutter 1992, 1993).

The hydrous polycrystalline MM (D03IB068) contains serpentine and saponite that would decompose to amorphous phases by brief heating at 600 and $700{ }^{\circ} \mathrm{C}$, respectively (Nozaki et al. 2006). The decomposition of saponite could be preceded by shrinkage of interlayer spacing from $1.32 \mathrm{~nm}$ due to loss of water at $600{ }^{\circ} \mathrm{C}$ (Nozaki et al. 2006). Our TEM observation revealed that part of the saponite in this MM shrunk to $0.90 \mathrm{~nm}$ (Fig. 6b). Therefore, D03IB068 should have experienced atmospheric entry heating with a peak temperature of $\sim 600{ }^{\circ} \mathrm{C}$.

The other least heated MM, D03IB067, is composed of anhydrous minerals. Although the constituent minerals are less sensitive to thermal alteration than hydrous minerals, some constraint on the peak temperature is indicated by the presence of SF tracks in the olivine and pyroxene grains in this MM. Fraundorf et al. (1982) reported that SF tracks in olivine become difficult to detect after pulse heating in the range of $500-600{ }^{\circ} \mathrm{C}$, whereas those in pyroxene can survive pulse heating at $625^{\circ} \mathrm{C}$ but disappear after $700{ }^{\circ} \mathrm{C}$. Considering these experimental results by Fraundorf et al. (1982), the peak temperature of D03IB067 is regarded as lower than $\sim 600{ }^{\circ} \mathrm{C}$.

\section{Moderately and severely heated MMs}

Based on the noble gas release profiles (Fig. 1), the moderately and severely heated MMs should have experienced atmospheric heating with peak temperatures $>650{ }^{\circ} \mathrm{C}$ 


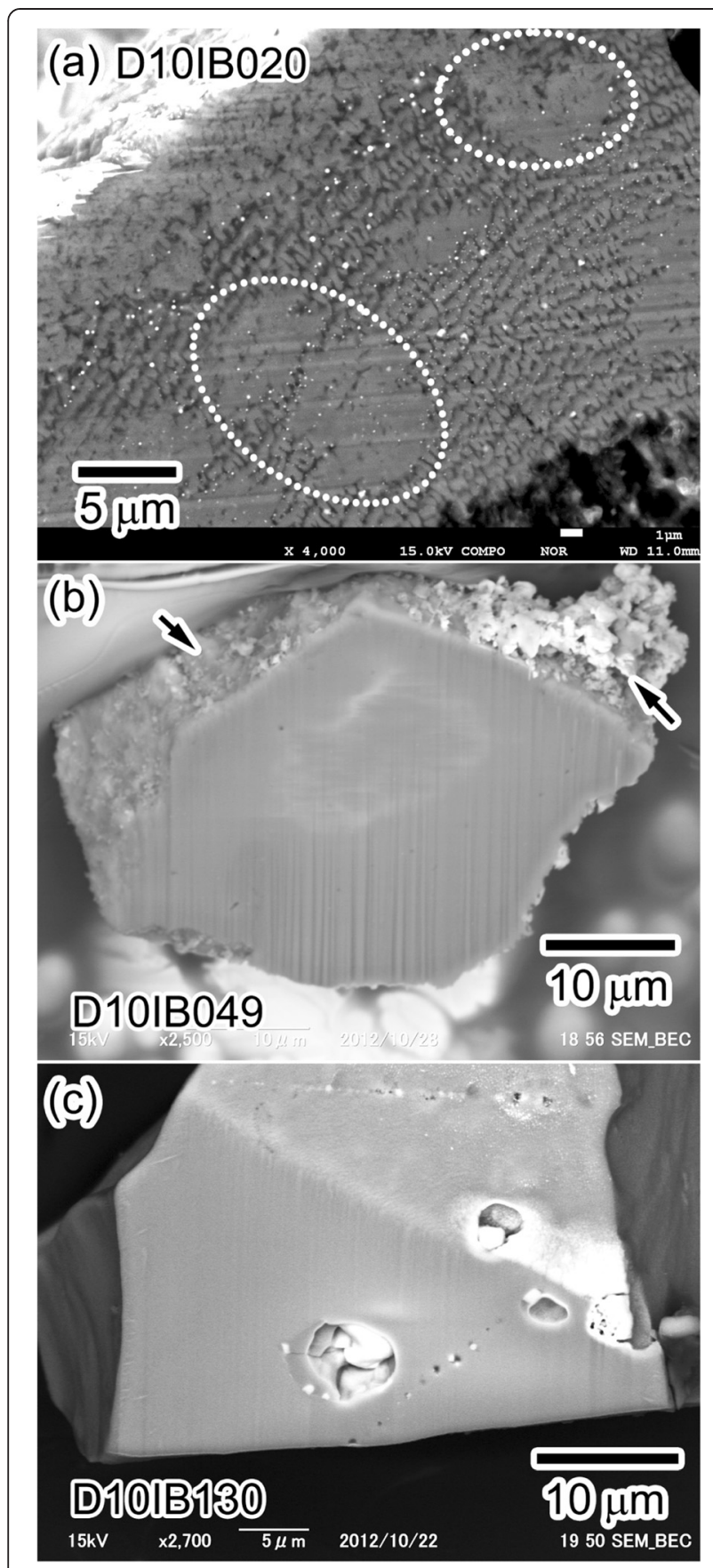

Fig. 8 Back scattered electron (BSE) images of the cross sections of the moderately heated micrometeorites (MMs) investigated in this study. a D10IB020 has a texture similar to a cryptocrystalline chondrule. The fern-like texture is composed of olivine (brighter) and glass (darker). The patchy areas indicated by dotted ellipsoids consist of high-Ca pyroxene, olivine, and glass. b D10IB049 is composed of low-Ca pyroxene. Fine-grained materials attached on its original surface (indicated by arrows) consist of olivine, magnetite, and pyrrhotite. c An enlarged image of D10IB130, composed of single a olivine crystal showing arrays of $\sim 1-\mu \mathrm{m}$ holes and some discrete $3-5-\mu \mathrm{m}$ holes because the cumulative releases of ${ }^{4} \mathrm{He}$ in the 400 and $650{ }^{\circ} \mathrm{C}$ fractions are much lower than $50 \%$. It is difficult to estimate the peak temperatures for each MM. If it is assumed that the moderately heated MMs have initially contained ${ }^{4} \mathrm{He}$ at the maximum (saturated) concentration of $10^{-1}-10^{-2} \mathrm{~cm}^{3}$ STP SW- ${ }^{4} \mathrm{He} / \mathrm{g}$ in particles $\sim 50 \mu \mathrm{m}$ in diameter (e.g., Bogard 1977; Jull and Pillinger 1977; Signer et al. 1977), the present ${ }^{4} \mathrm{He}$ concentrations correspond to $10^{-1}-10^{-3}$ of the initial concentrations (Table 2). According to the results of stepped extraction experiments, most of noble gases are extracted below $\sim 900^{\circ} \mathrm{C}$ from lunar soil (Nier and Schlutter 1992; Fu et al. 2013) and synthetic olivine irradiated by ${ }^{4} \mathrm{He}$ with $50-\mathrm{keV}$ kinetic energy (Fu et al. 2013). Hence, the peak temperatures for the moderately heated MMs are likely between 650 and $900{ }^{\circ} \mathrm{C}$. For the severely heated MMs, the observed concentrations of ${ }^{4} \mathrm{He}$ are 10 to 100 times lower than those for the moderately heated MMs and correspond to $10^{-2}-10^{-5}$ of the hypothetical initial concentrations. Hence, the peak temperatures of the severely heated MMs are $>900{ }^{\circ} \mathrm{C}$.

The mineralogical features determined by our TEM observation put constraints on the peak temperatures for the severely heated MMs. The appearance of olivine and glass at the outermost edge of D03IB057 suggests that this MM had been partly melted (Fig. 10a). The twinned clinopyroxene in the interior likely converted from proto-pyroxene stable at temperatures of about $1000-1450^{\circ} \mathrm{C}$, which depends on the Fe content (Huebner 1980). The mineralogical features of D03IB057 suggest that this MM experienced strong heating and rapid cooling. The textures of the magnetite and glass patches observed in D10IB170 are quite similar to that produced by heating of olivine under oxidized conditions (Wu and Kohlstedt 1988), suggesting that they were formed by decomposition of olivine under oxidizing conditions at temperatures higher than $1000{ }^{\circ} \mathrm{C}(\mathrm{Wu}$ and Kohlstedt 1988; Gualtieri et al. 2003).

\section{Formation of secondary magnetite and diffusive loss of He during atmospheric entry heating}

As observed in the severely heated MMs, the presence of secondary magnetite is indicative of strong heating during atmospheric entry. However, a moderately heated MM, D10IB130, also contains abundant wormy secondary magnetite crystals (Fig. 9d, e). This mineralogical feature of D10IB130 appears to contradict the noble-gas characteristics. Here, we determine whether the magnetite formation by the atmospheric heating is compatible with the retention of He in this MM.

According to Wu and Kohlstedt (1988), magnetite formation is controlled by self-diffusion of $\mathrm{Fe}^{2+}$, which is comparable to $\mathrm{Mg}$ self-diffusion. As discussed above, D10IB130 appears to have been heated to $650-900{ }^{\circ} \mathrm{C}$. By assuming the $\mathrm{Mg}$ diffusion rate shown by $\mathrm{Wu}$ and 


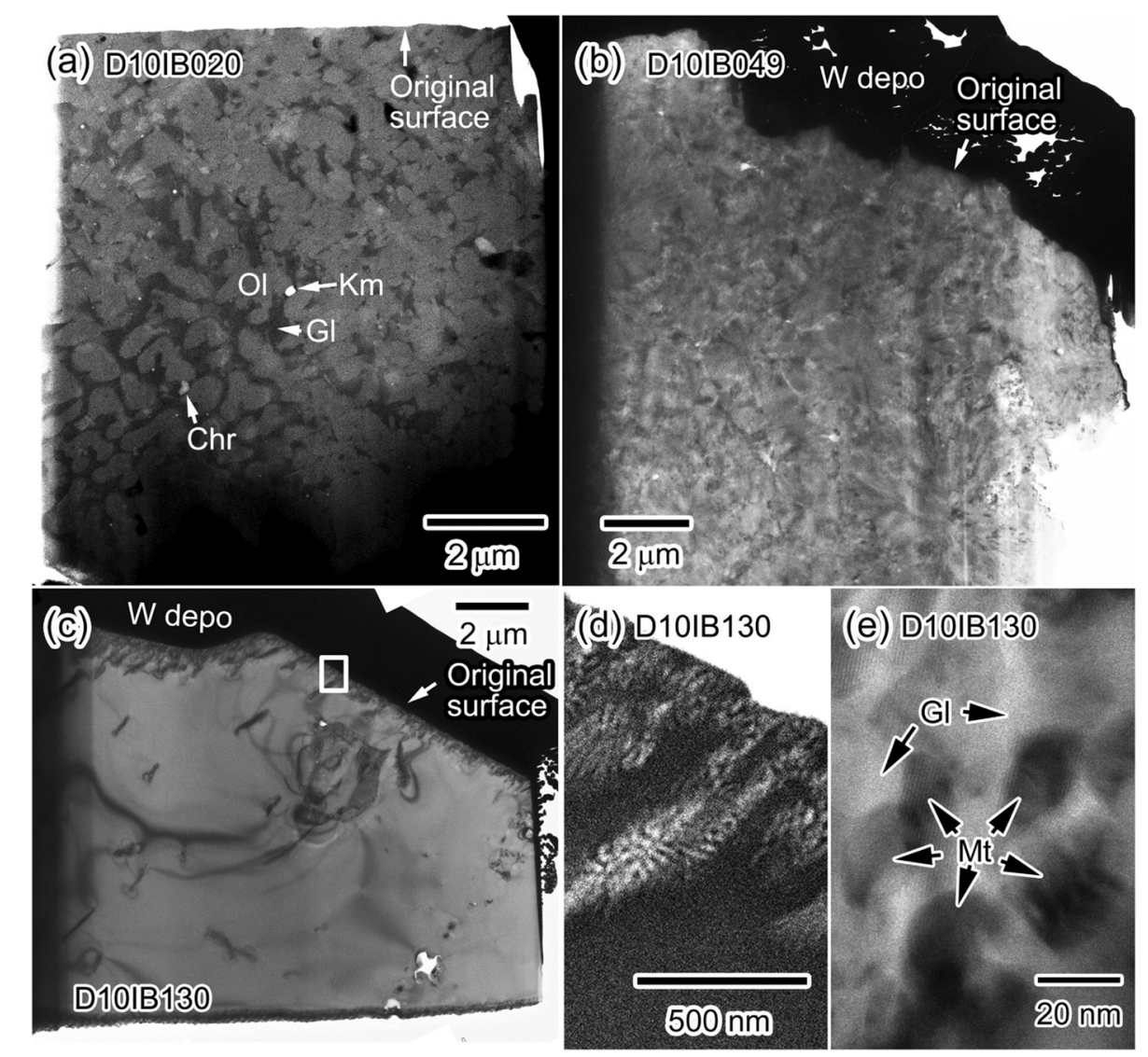

Fig. 9 Transmission electron microscopy (TEM) images of moderately heated micrometeorites (MMs). a High-angle annular diffraction-scanning transmission electron microscope (HAADF-STEM) image of D101B020, containing abundant olivine (OI) and interstitial glass (GI) with small amounts of kamacite (Km) and chromite (Chr). Bright-field images of b D10IB049, composed of <2- $\mu \mathrm{m}$ low-Ca pyroxene and $\mathbf{c}$ D10IB130, composed of a single olivine crystal. $\mathbf{d}$ HAADF-STEM image of an enlarged area indicated by the boxed area in (c). Wormy magnetite crystals (white) have developed at the original surface, which is the boundary between wormy magnetite-rich areas and upper right white area, which is W deposition protecting the surface during focused ion beam (FIB) processing. The magnetite was likely formed by atmospheric entry heating and oxidation. e Bright-field image of wormy magnetite crystals (Mt) embedded in glass (Gl)

Kohlstedt (1988), the heating duration necessary to form the observed magnetite, assumed to be $\sim 10 \mathrm{~nm}$ (Fig. 9e), was calculated to be 6500 and $100 \mathrm{~s}$ at 650 and $900{ }^{\circ} \mathrm{C}$, respectively, under the ground atmosphere pressure. Such prolonged heating is impossible because particles with $\sim 50-\mu \mathrm{m}$ diameter and initial velocities of 15 and $20 \mathrm{~km} / \mathrm{s}$ can experience peak heating only for $10-20 \mathrm{~s}$ at altitudes of $85-90 \mathrm{~km}$ (Love and Brownlee 1991). To reproduce 10-nm-sized magnetite within a short heating duration such as $20 \mathrm{~s}$, a heating temperature of around $1100-1200{ }^{\circ} \mathrm{C}$ is necessary (Wu and Kohlstedt 1988), although this temperature range is inconsistent with the noble-gas release pattern of D10IB130 (Fig. 1). Even if the peak temperature expected for this $\mathrm{MM}$ based on the release pattern is underestimated, heating at $1100{ }^{\circ} \mathrm{C}$ for $10 \mathrm{~s}$ would release most of the SW noble gases implanted in the MMs because of the $\sim 0.04-\mu \mathrm{m}$ typical penetration depth of SW-He (1 keV/nucleon) and the typical diffusion length of He in olivine $(0.1 \mu \mathrm{m}$ for heating at $1100{ }^{\circ} \mathrm{C}$ for $10 \mathrm{~s}$; Trull and Kurz 1993). In addition to diffusion, the loss of noble gases could take place by abrasion or evaporation of the outermost layer of MMs during atmospheric entry.

Even worse, the estimated duration for the magnetite formation should be the lower limit because the formation rate of magnetite is dependent also on the oxygen pressure. The oxygen pressure at the altitude $\left(P_{\text {fly }}\right)$ at which extraterrestrial particles have experienced the maximum heating temperature is calculated by $P_{\mathrm{fly}}=\rho v^{2}$, where $\rho$ and $v$ are the oxygen density and the particle entry velocity at the relevant altitude, respectively. The $P_{\text {fly }}$ at $85-90 \mathrm{~km}$ of altitudes and with $15-20 \mathrm{~km} / \mathrm{s}$ of the entry velocity is about one to two orders lower than the oxygen pressure on the ground, according to the density data provided by the United States Standard Atmosphere of 1976 and by assuming that the oxygen partial pressure 


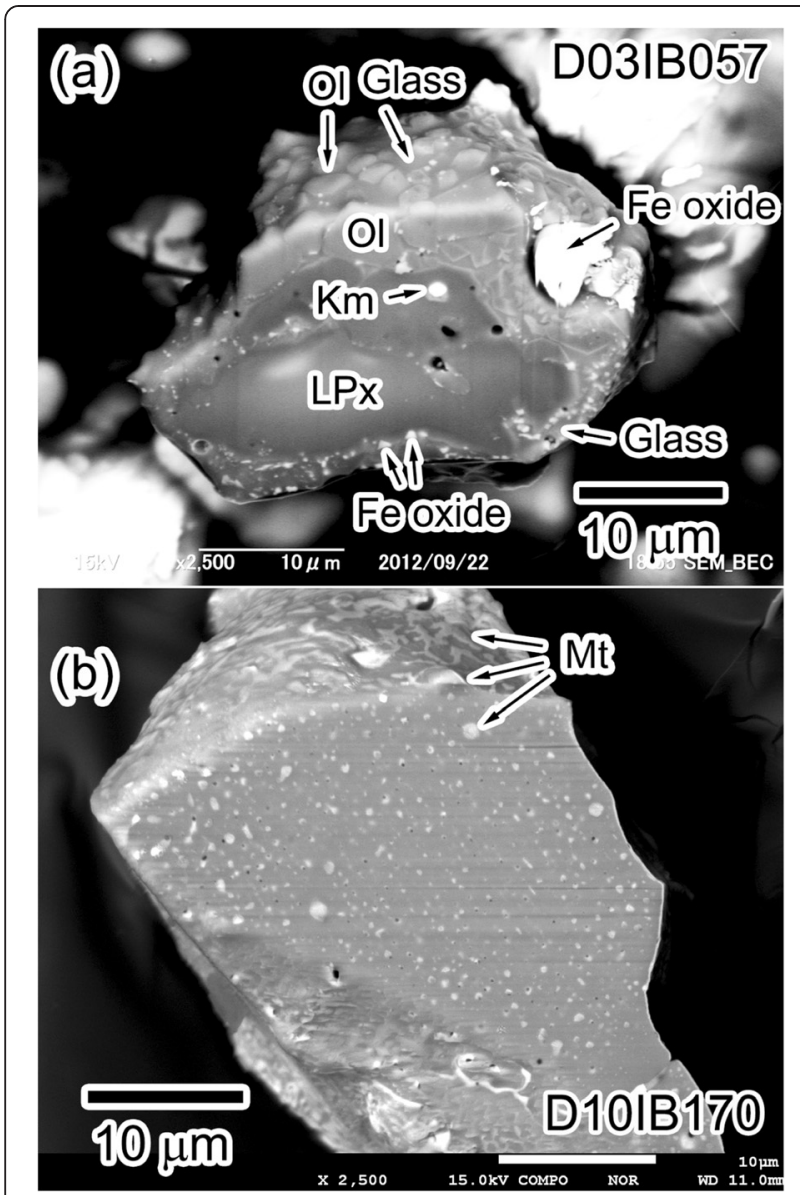

Fig. 10 Back scattered electron (BSE) images of the cross sections of the severely heated micrometeorites (MMs) investigated in this study. a D03IB057 shows a porphyritic texture composed of a core of magnesian low-Ca pyroxene ( $(\mathrm{PX})$ and a kamacite $(\mathrm{Km})$ inclusion. The rim is composed of ferroan olivine (Ol), Fe oxide, and glass (Gl). b D10IB170 is composed of a single olivine crystal containing many magnetite grains

does not depend on altitude. This calculation indicates that the magnetite formation at a high altitude would be slower than that on the ground.

Hence, some mechanisms are necessary for accelerating the oxidation of olivine to compensate for the discrepancy between the formation rate of magnetite and the loss rate of noble gases in a peculiar situation of atmospheric entry heating caused by interaction between hypervelocity particles and atmospheric molecules. The flow of $\mathrm{O}_{2}$ molecules encountering the surface of dust particles or active oxygen atoms and compounds might accelerate the formation rate of magnetite during atmospheric entry.

\section{Excess ${ }^{3} \mathrm{He}$ in a moderately heated coarse-grained MM}

The isotopic ratios of $\mathrm{He}$ in most of the MMs studied are essentially identical to the SW values, ${ }^{3} \mathrm{He} /{ }^{4} \mathrm{He}=$
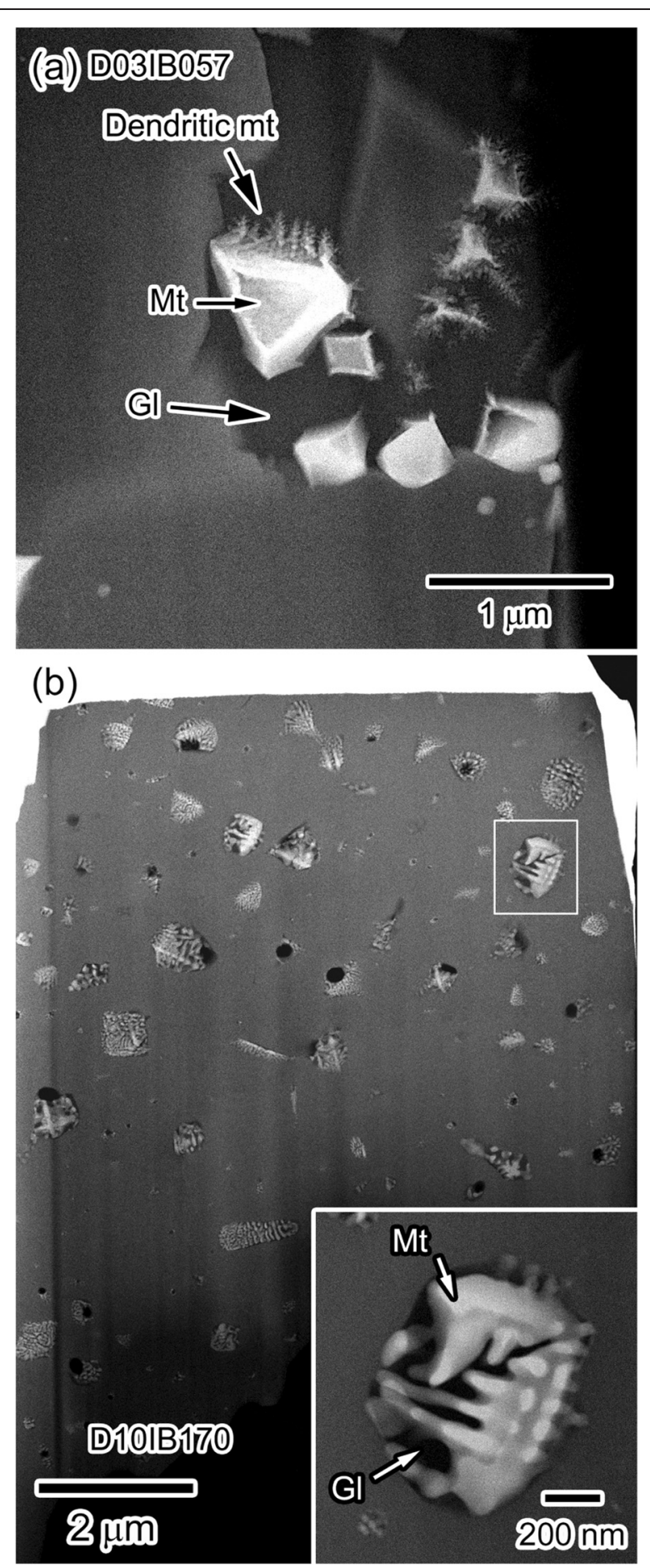

Fig. 11 High-angle annular diffraction-scanning transmission electron microscope (HAADF-STEM) images of the severely heated micrometeorites (MMs.) a Euhedral magnetite crystals (Mt) and interstitial glass (Gl) near the original surface of D03IB057. Dendritic magnetite (Dendritic $\mathrm{mt}$ ) overgrowth on the surface of the euhedral magnetite crystals. b Olivine in D10IB170 contains abundant patches composed of magnetite and glass. The inset shows an enlarged HAADF-STEM image of a magnetite-glass (Gl) patch 
$4.64 \times 10^{-4}$ (Heber et al. 2009), although the ${ }^{3} \mathrm{He} /{ }^{4} \mathrm{He}$ ratio of D10IB130, $8.44 \times 10^{-4}$, is clearly higher than the SW ratio (Table 2 and Fig. $3 b$ ). Although it might be expected that the high ${ }^{3} \mathrm{He} /{ }^{4} \mathrm{He}$ ratio is the result of long exposure to GCRs (i.e., large contribution of cosmogenic isotopes), it is impossible to explain the ${ }^{21} \mathrm{Ne} /{ }^{22} \mathrm{Ne}$ ratio that is not indicative of cosmogenic ${ }^{21} \mathrm{Ne}$ excess. In the following discussion, we will show that the $\mathrm{He}$ and $\mathrm{Ne}$ isotopic ratios in D10IB130 are explained by the contribution of solar energetic particles rather than by mixing of SW and cosmogenic noble-gas components. In the mixing calculation explained below, the ${ }^{4} \mathrm{He} /{ }^{20} \mathrm{Ne}$ ratios observed in the MMs do not have to be reproduced because the measured ${ }^{4} \mathrm{He} /{ }^{20} \mathrm{Ne}$ ratios of the MMs could have been altered and lowered (i.e., depleted in ${ }^{4} \mathrm{He}$ ) during the atmospheric heating to varying degrees. Moreover, the fractionation effects would be considerable in elemental ratios, as expected from Fig. 2, but small in isotopic ratios.

As shown in Fig. 3b, the isotopic ratios of $\mathrm{He}$ and $\mathrm{Ne}$ in the least and moderately heated MMs can be explained by mixing of normal SW and implantation fractionation in regard to both elemental and isotopic ratios (Grimberg et al. 2006, 2008; Wieler et al. 2007) of SW represented in lunar ilmenite, designated as IFSW in Fig. 3, except for D10IB130. Some Antarctic MMs show ${ }^{3} \mathrm{He} /{ }^{4} \mathrm{He}$ ratios larger than $5 \times 10^{-4}$ (Osawa and Nagao 2002, Osawa et al. 2003a), which can be explained by mixing of normal SW and GCR-produced components, as clearly presented in Fig. 3b. Although the data for D03IB068 and D10IB049 slightly deviate from the mixing line between SW and IFSW, the deviation can be explained by the addition of a very small amount of a GCR-produced component, corresponding to about 5 Myr and 0.1 Myr exposure for D03IB068 and D10IB049, respectively. When a more fractionated ${ }^{4} \mathrm{He} /{ }^{20} \mathrm{Ne}$ ratio of $\sim 100$ is assumed for IFSW, the GCR exposure is not necessary to compensate for the deviation between the data for D03IB068 and D10IB049 and the mixing line. Such a highly fractionated SW (i.e., low ${ }^{4} \mathrm{He} /{ }^{20} \mathrm{Ne}$ of $\sim 100$ but ${ }^{20} \mathrm{Ne} /{ }^{22} \mathrm{Ne}$ similar to the IFSW value) is possible for olivine (e.g., Kiko et al. 1978; Signer et al. 1977; Wieler et al. 1980).

However, the isotopic composition of $\mathrm{He}$ and $\mathrm{Ne}$ in D10IB130 cannot be explained by the mixing of SW, IFSW, and GCR-produced components (Fig. 1b). When an elementally fractionated (i.e., depleted in $\mathrm{He}$ ) but isotopically unfractionated component is assumed instead of the normal SW, the isotopic ratios of D10IB130 can be reproduced to some degree. Such an elementally fractionated SW has been observed in olivine grains recovered from the Itokawa asteroid by the Hayabusa spacecraft (Nagao et al. 2011). Two Itokawa particles, RA-QD020015 and RA-QD02-0065, have solar-like ${ }^{3} \mathrm{He} /{ }^{4} \mathrm{He}$ and
${ }^{20} \mathrm{Ne} /{ }^{21} \mathrm{Ne} /{ }^{22} \mathrm{Ne}$ ratios but are associated with elementally fractionated ${ }^{4} \mathrm{He} /{ }^{20} \mathrm{Ne}$ ratios (110-127). Mixing of the elementally fractionated SW and a GCR-produced component reduces the degree of the ${ }^{3} \mathrm{He}$ excess, but an excess corresponding to $150 \mathrm{Myr}$ exposure to GCRs remains. Moreover, the mixing of the Itokawa particle composition and a GCR-produced component results in ${ }^{21} \mathrm{Ne}$ excess $\left({ }^{21} \mathrm{Ne} /{ }^{22} \mathrm{Ne}\right.$ of 0.08 at ${ }^{3} \mathrm{He} /{ }^{4} \mathrm{He}$ of $8.44 \times 10^{-4}$ or 0.05 at ${ }^{20} \mathrm{Ne} /{ }^{22} \mathrm{Ne}$ of 12.83), contradicting the observation (Table 2 and Fig. 3a). The contribution of a solar cosmic ray (SCR)-produced component is excluded because the SCR-produced ${ }^{3} \mathrm{He} /{ }^{4} \mathrm{He}$ ratio of 0.03 (calculated from Trappitsch and Leya 2013) is lower than the GCRproduced value, which makes the situation worse.

Therefore, we argue that the ${ }^{3} \mathrm{He}$ excess in D10IB130 originated from a component having solar-like $\mathrm{Ne}$ isotopic ratios and a higher ${ }^{3} \mathrm{He} /{ }^{4} \mathrm{He}$ ratio than the SW value. Such a component is expected in solar energetic particles emitted by gradual coronal mass ejection (CME) or impulsive SF events that enhance the ${ }^{3} \mathrm{He} /$ ${ }^{4} \mathrm{He}$ ratio by a factor of 5 in CME events (Mason et al. 1999) or by factors of 250 to 80,000 in SF events (Reames 1998; Miller 1998). In this case, long exposure to cosmic rays is not necessary, and the noble-gas composition in this MM can be attributed to the mixing of a solar energetic particle component and a normal or fractionated SW component. To evaluate our argument, it is necessary to determine the precise $\mathrm{Ne}$ isotopic ratios and the $\mathrm{He} / \mathrm{Ne}$ elemental ratio for the solar energetic particle component by space craft/satellite observations or by theoretical calculations in the future. To avoid misunderstanding, it is important to confirm that SEP noble gas is not a component related to SF or CME events but is merely normal SW fractionated during implantation (e.g., Grimberg et al. 2006, 2008; Wieler et al. 2007). The isotopic ratios of the SEP noble gas are enriched in heavier isotopes (i.e., lower ${ }^{3} \mathrm{He} /{ }^{4} \mathrm{He}$ and ${ }^{20} \mathrm{Ne} /{ }^{22} \mathrm{Ne}$ ratios compared with those of normal SW, as shown in Fig. 3), which is opposite that observed in D10IB130.

As discussed above, the high ${ }^{3} \mathrm{He} /{ }^{4} \mathrm{He}$ ratio of D10IB130 is likely indicative of the contribution of solar energetic particles in this MM. Similar or even higher ${ }^{3} \mathrm{He} /{ }^{4} \mathrm{He}$ ratios have been observed relatively often in IDPs (Pepin et al. 2000, 2001), although it is not conclusive because of the absence of Ne isotope data for these IDPs. In contrast, numerous studies on lunar soils have determined that there is no evidence for the contribution of solar energetic particles and that the isotopic ratios of solar wind have been quite constant (e.g., Heber et al. 2001). It is possible that the difference in duration of exposure to solar particles is responsible for the absence of ${ }^{3} \mathrm{He}$-rich signatures in lunar samples because shorter exposure durations of MMs and IDPs increase the odds of detecting such sudden 
events. The SW exposure duration of IDPs reported by Pepin et al. (2000) is calculated to be in the order of 10010,000 years at $1 \mathrm{AU}$ based on the ${ }^{20} \mathrm{Ne}$ concentrations and the SW flux (Heber et al. 2009), which is shorter than those of lunar soils that have been exposed to SW typically for $10^{4}-10^{5}$ years (Signer et al. 1977; Wieler et al. 1983). In addition to the duration of exposure, the magnetic field of the Earth influences the irradiation conditions on the lunar surface. The propagation ranges of protons and other ions in the impulsive SF events are narrow compared with those in the gradual CME events (e.g., Reames 1999); thus, more ${ }^{3} \mathrm{He}$-enriched SF particles were partly prevented from arriving at the Moon. Consequently, the ${ }^{3} \mathrm{He}$-rich signature observed in D10IB130 is more likely to originate from impulsive SF events rather than CME events.

\section{Atmospheric entry velocity and origin of MMs}

Based on the $50 \%$ release temperature (Nier and Schlutter 1992, 1993), Joswiak et al. (2005) calculated the peak temperatures experienced by IDPs during atmospheric entry and divided IDPs in two categories as those having peak temperatures $>700$ and $<500{ }^{\circ} \mathrm{C}$. The IDPs studied by Joswiak et al. (2005) are within 5-15 $\mu \mathrm{m}$ in size; hence, they assumed that the peak temperatures are correlated mainly with atmospheric entry velocity. The particles with higher peak temperatures were believed to have velocities of $\geq 18 \mathrm{~km} / \mathrm{s}$, and those with lower temperature have $\leq 14 \mathrm{~km} / \mathrm{s}$. The differences in atmospheric entry velocities are considered to result from differences in their parent bodies, i.e., particles with higher velocities are from comets and those with lower velocities are from asteroids.

Considering our estimates for the peak temperatures discussed above, it is possible that the least heated MMs originated from asteroids and the severely heated MMs came from comets. Peak temperatures for the moderately MMs are intermediate between the criterion temperatures, i.e., between 500 and $700{ }^{\circ} \mathrm{C}$; hence it is difficult to distinguish whether the moderately heated MMs originated from asteroids or comets based only on the peak temperature. Therefore, other criteria are needed to distinguish the origins of interplanetary particles. One possible source of information is the ratio of SW- and GCR-produced gases because the SW flux depends on the distance from the Sun whereas the GCR flux is virtually constant within the solar system. Differences in averaged distance from the Sun during interplanetary flights of particles could be determined as SW/GCR-produced abundance ratios (e.g., ${ }^{20} \mathrm{Ne}-\mathrm{SW} /$ ${ }^{21} \mathrm{Ne}-\mathrm{GCR}$ ratios). Such a ${ }^{21} \mathrm{Ne}-\mathrm{GCR}$ signature can be observed only in IDPs and MMs with relatively long GCR exposure ages of $>\sim 10$ Myr (e.g., Pepin et al. 2000, 2001; Osawa et al. 2003b). As previously mentioned, longer GCR exposure ages are expected for cometary particles considering the Poynting-Robertson effect.

\section{Conclusions}

Seven MMs recovered from Antarctic snow are classified into three types based on their noble-gas release patterns reflecting the degree of heating during the atmospheric entry. This classification is consistent with the mineralogical and petrographic features of the MMs.

A moderately heated MM, D10IB130, shows a ${ }^{3} \mathrm{He} /{ }^{4} \mathrm{He}$ ratio of $8.44 \times 10^{-4}$ but no cosmogenic ${ }^{21} \mathrm{Ne}$ signature. This can be explained by the addition of a ${ }^{3} \mathrm{He}$-enrich component related to solar energetic particle events such as flare events. This result may be attributed to a short exposure to solar wind and/or a terrestrial magnetic field.

\section{Competing interests}

The authors declare that they have no competing interests.

\section{Authors' contributions}

$\mathrm{RO}$ conducted the noble-gas studies, participated in the sequence alignment, and drafted the manuscript. TNo conducted the TEM, micro-Raman studies, and FIB sectioning; participated in the sequence alignment; and drafted the manuscript. STs conducted the sample preparation and FIB sectioning. YT conducted the noble-gas studies. TNa conducted the SR-XRD studies, participated in the sequence alignment, and drafted the manuscript. ME, SI, STa, KT, and HY participated in the sequence alignment and drafted the manuscript. HN participated in the design of the study. All authors read and approved the final manuscript.

\section{Acknowledgements}

We are grateful to H. Motoyama, N. Imae, and the JARE teams for collection and transportation of the Antarctic snow. We thank A. Okubo for her assistance with the sample collection. Reviews by two anonymous reviewers resulted in significant improvements to this paper. This work was supported by Grant-in-Aid for Scientific Research (S) (No. 22224010, PI: H. Nagahara) and partly by a Grant-in-Aid for Young Scientists (A) (No. 23684046, PI: R. Okazaki).

\section{Author details}

${ }^{1}$ Department of Earth and Planetary Sciences, Faculty of Sciences, Kyushu University, 33, Hakozaki, Higashi-ku, Fukuoka 812-8581, Japan. ${ }^{2}$ Faculty of Arts and Science, Kyushu University, 744, Motooka, Nishi-ku, Fukuoka 819-0395, Japan. ${ }^{3}$ College of Science, Ibaraki University, 2-1-1, Bunkyo, Mito 310-8512, Japan. ${ }^{4}$ Department of Earth and Planetary Sciences, Graduate School of Sciences, Kyushu University, 33, Hakozaki, Higashi-ku, Fukuoka 812-8581, Japan. ${ }^{5}$ Department of the Earth and Planetary Material Science, Tohoku University, Sendai, Miyagi 980-8578, Japan. ${ }^{6}$ Department of Chemistry, Tokyo Metropolitan University, 1-1 Minami-Osawa, Hachioji, Tokyo 192-0397, Japan. ${ }^{7}$ Department of Geology and Mineralogy, Faculty of Science, Kyoto University, Kitashirakawaoiwake-cho, Sakyo-ku, Kyoto 606-8502, Japan. ${ }^{8}$ Department of Earth and Planetary Science, The University of Tokyo, 7-3-1 Hongo, Bunkyo-ku, Tokyo 113-0033, Japan. 'Department of Natural History Sciences, Hokkaido University, N10W8, Kita-ku, Sapporo 060-0810, Japan.

${ }^{10}$ Department of Earth and Space Science, Osaka University, 1-1

Machikaneyama, Toyonaka, Osaka 560-0043, Japan.

Received: 10 December 2014 Accepted: 3 June 2015

Published online: 17 June 2015

\section{References}

Bajo K, Akaida T, Ohashi N, Noguchi T, Nakamura T, Nakamura Y, Sumino H, Nagao K (2011) Single grain noble gas analysis of Antarctic

micrometeorites by stepwise heating method with a newly constructed miniature furnace. Earth Planets Space 63:1097-1111.

Benkert JP, Baur H, Signer P, Wieler R (1993) He, Ne, and Ar from the solar wind and solar energetic particles in lunar ilmenites and pyroxenes. J Geophys Res 98(E7):13147-13162. 
Bogard D (1977) Effects of soil maturation on grain size-dependence of trapped solar gases. Proc Lunar Sci Conf 8:3705-3718.

Fraundorf $P$, Lyons T, Schubert $P$ (1982) The survival of solar flare tracks in interplanetary dust silicates on deceleration in the Earth's atmosphere. J Geophys Res 87(supplement):A409-A412.

Fu XH, Zou YL, He HY, Zheng YC, Li CL, Liu XQ (2013) Diffusion kinetic and retentivity of implanted helium in minerals. Lunar Planetary Sci Conf 44:1389.

Füri E, Aléon-Toppani A, Marty B, Libourel G (2013) Effects of atmospheric entry heating on the noble gas and nitrogen content of micrometeorites. Earth Planet Sci Lett 377-378:1-12.

Greshake A, Klöck W, Arndt P, Maetz M, Flynn GJ, Bajt S, Bischoff A (1998) Heating experiments simulating atmospheric entry heating of micrometeorites: clues to their parent body sources. Meteorit Planet Sci 33:267-290.

Grimberg A, Baur H, Bochsler P, Bühler F, Burnett DS, Hays C, Heber VS, Jurewicz AJG, Wieler R (2006) Solar wind neon from Genesis: implications for the lunar noble gas record. Science 314:1133-1135.

Grimberg A, Baur H, Bühler F, Bochsler P, Wieler R (2008) Solar wind helium, neon, and argon isotopic and elemental composition: data from the metallic glass flown on NASA's Genesis mission. Geochim Cosmochim Acta 72:626-645

Gualtieri AF, Gemmi M, Dapiaggi M (2003) Phase transformations and reaction kinetics during the temperature-induced oxidation of natural olivine. Am Mineral 88:1560-1574.

Harries D, Langenhorst F (2014) The mineralogy and space weathering of a regolith grain from 25143 Itokawa and the possibility of annealed solar wind damage. Earth Planets Space 66:163.

Heber VS, Baur H, Wieler R (2001) Is there evidence for a secular variation of helium isotopic composition in the solar wind? Meteorit Planet Sci 36(suppl):A76-A77.

Heber VS, Wieler R, Baur H, Olinger C, Friedmann TA, Burnet DS (2009) Noble gas composition of the solar wind as collected by the Genesis mission. Geochimica et Cosmochimica Act 73:7414-7432.

Huang E, Chen CH, Huang T, Lin EH, Xu JA (2000) Raman spectroscopic characteristics of Mg-Fe-Ca pyroxenes. Am Mineral 85:473-479.

Huebner JS (1980) Pyroxene phase equilibria at low pressure. In: Prewitt CT (ed) Pyroxenes, vol 7, Reviews in Mineralogy. The Mineralogical Society of America, Washington, pp 213-288.

Joswiak DJ, Brownlee DE, Pepin RO, Schlutter DJ (2005) Mineralogy and densities of cometary and asteroidal IDPs collected in the stratosphere, Workshop on Dust in Planetary Systems 2005., abstract \#4106.

Jull AJT, Pillinger CT (1977) Effects of sputtering on solar wind element accumulation. Proc Lunar Sci Conf 8:3817-3833.

Kehm K, Flynn GJ, Sutton SR, Hohenberg CM (2002) Combined noble gas and trace element measurements on individual stratospheric interplanetary dust particles. Meteorit Planet Sci 37:1323-1335.

Keller LP, Berger EL (2014) A transmission electron microscope study of Itokawa regolith grains. Earth Planets Space 66:71.

Keller LP, Thomas KL, McKay DS (1992) An interplanetary dust particle with links to Cl chondrite. Geochim Cosmochim Acta 56:1409-1412.

Kiko J, Kirsten T, Ries D (1978) Distribution properties of implanted rare gases in individual olivine crystals from the lunar regolith. Proc Lunar Sci Conf 9:1655-1665.

Kurat G, Koeberl C, Presper T, Brandstätter F, Maurette M (1994) Petrology and geochemistry of Antarctic micrometeorites. Geochim Cosmochim Acta 58:3879-3904.

Kurz MD, Jenkins WJ (1981) The distribution of helium in oceanic basalt glasses. Earth Planet Sci Lett 53:41-54.

Langenhorst F, Harries D, Pollok K, van Aken PA (2014) Mineralogy and defect microstructure of an olivine-dominated Itokawa dust particle: evidence for shock metamorphism, collisional fragmentation, and LL chondrite origin. Earth Planets Space 66:118.

Leya I, Masarik J (2009) Cosmogenic nuclides in stony meteorites revisited. Meteorit Planet Sci 44:1061-1086.

Love SG, Brownlee DE (1991) Heating and thermal transformation of micrometeorites entering the Earth's atmosphere. Icarus 89:26-43.

Love SG, Brownlee DE (1993) A direct measurement of the terrestrial mass accretion rate of cosmic dust. Science 262:550-553.

Love SG, Brownlee DE (1994) Peak atmospheric entry temperatures of micrometeorites. Meteoritics 29:69-70.
Mason GM, Mazur JE, Dwyer JR (1999) ${ }^{3}$ He enhancements in large solar energetic particle events. Astrophysical J 525:L133-L136.

Mikouchi T, Komatsu M, Hagiya K, Ohsumi K, Zolensky ME, Hoffmann V, Martinez J, Hochleitner R, Kaliwoda M, Terada Y, Yagi N, Takata M, Satake W, Aoyagi Y, Takenouchi A, Karouji Y, Uesugi M, Yada T (2014) Mineralogy and crystallography of some Itokawa particles returned by the Hayabusa asteroidal sample return mission. Earth Planets Space 66:82.

Miller JA (1998) Particle acceleration in impulsive solar flares. Space Sci Rev 86:79-105.

Nagao K, Okazaki R, Nakamura T, Miura YN, Osawa T, Bajo K, Matsuda S, Ebihara M, Ireland TR, Kitajima F, Naraoka H, Noguchi T, Tsuchiyama A, Yurimoto H, Zolensky ME, Uesugi M, Shirai K, Abe M, Yada T, Ishibashi Y, Fujimura A, Mukai T, Ueno M, Okada T, Yoshikawa M, Kawaguchi I (2011) Irradiation history of Itokawa regolith material deduced from noble gases in the Hayabusa samples. Science 333:1128-1131.

Nakamura T, Noguchi T, Tanaka M, Zolensky ME, Kimura M, Tsuchiyama A, Nakato A, Ogami T, Ishida H, Uesugi M, Yada T, Shirai K, Fujimura A, Okazaki R, Sandford SA, Ishibashi Y, Abe M, Okada T, Ueno M, Mukai T, Yoshikawa M, Kawaguchi J (2011) Itokawa dust particles: A direct link between S-type asteroids and ordinary chondrites. Science 333:1113-1116.

Nakamura E, Makishima A, Moriguti T, Kobayashi K, Tanaka R, Kunihiro T, Tsujimori T, Sakaguchi C, Kitagawa H, Ota T, Yachi Y, Yada T, Abe M, Fujimura A, Ueno M, Mukai T, Yoshikawa M, Kawaguchi J (2012) Space environment of an asteroid preserved on micrograins returned by the Hayabusa spacecraft. Proc Natl Acad Sci 109:E624-E629.

Nier AO, Schlutter DJ (1990) Helium and neon isotopes in stratospheric particles. Meteoritics 25:263-267.

Nier AO, Schlutter DJ (1992) Extraction of helium from individual interplanetary dust particles by step-heating. Meteoritics 27:166-173.

Nier AO, Schlutter DJ (1993) The thermal history of interplanetary dust particles collected in the Earth's stratosphere. Meteoritics 28:675-681.

Noguchi T, Nakamura T, Kimura M, Zolensky ME, Tanaka M, Hashimoto T, Konno M, Nakato A, Ogami T, Fujimura A, Abe M, Yada T, Mukai T, Ueno M, Okada T, Shirai K, Ishibashi Y, Okazaki R (2011) Incipient space weathering observed on the surface of Itokawa dust particles. Science 333:1121-1125.

Noguchi T, Kimura M, Hashimoto T, Konno M, Nakamura T, Zolensky ME, Okazak R, Tanaka M, Tsuchiyama A, Nakato A, Ogami T, Ishida H, Sagae R, Tsujimoto S, Matsumoto T, Matsumoto J, Fujimura A, Abe M, Yada T, Mukai T, Ueno M, Okada T, Shirai K, Ishibashi Y (2014a) Space weathered rims found on the surfaces of the Itokawa dust particles. Meteorit Planet Sci 49:188-214.

Noguchi T, Bridges JC, Hicks LJ, Gurman SJ, Kimura M, Hashimoto T, Konno M, Bradley JP, Okazaki R, Uesugi M, Yada T, Karouji Y, Abe M, Okada T, Mitsunari T, Nakamura T, Kagi H (2014b) Mineralogy of four Itokawa particles collected from the first touchdown site. Earth Planets Space 66:124.

Nozaki W, Nakamura T, Noguchi T (2006) Bulk mineralogical changes of hydrous micrometeorites during heating in the upper atmosphere at temperatures below $1000^{\circ} \mathrm{C}$. Meteoritics Planetary Sci 41:1095-1114.

Okazaki R, Nakamura T (2006) Mineralogy and oxygen isotopes of unmelted Antarctic micrometeorites. Lunar Planetary Science Conf 37:1510.

Osawa T, Nagao K (2002) Noble gas compositions of Antarctic micrometeorites collected at the Dome Fuji Station in 1996 and 1997. Meteoritics Planetary Sci 37:911-936.

Osawa T, Nakamura T, Nagao K (2003a) Noble gas isotopes and mineral assemblages of Antarctic micrometeorites collected at the meteorite ice field around the Yamato Mountains. Meteoritics Planetary Sci 38:1627-1640.

Osawa T, Nagao K, Noguchi T (2003b) Remnant extraterrestrial noble gases in Antarctic cosmic spherules. Antarctic Meteorite Res 16:196-219.

Ozima M, Podosek FA (2002) Noble Gas Geochemistry, 2nd edn. Cambridge University Press, Cambridge.

Pepin RO, Palma RL, Schlutter DJ (2000) Noble gases in interplanetary dust particles, I: the excess helium-3 problem and estimates of the relative fluxes of solar wind and solar energetic particles in interplanetary space. Meteoritics Planetary Sci 35:495-504.

Pepin RO, Palma RL, Schlutter DJ (2001) Noble gases in interplanetary dust particles, II: Excess helium-3 in cluster particles and modeling constraints on interplanetary dust particle exposures to cosmic-ray irradiation. Meteoritics Planetary Sci 36:1515-1534.

Reames DV (1998) Solar energetic particles: sampling coronal abundances. Space Sci Rev 85:327-340.

Reames DV (1999) Particle acceleration at the sun and in the heliosphere. Space Sci Rev 90:413-491. 
Sandford SA, Bradley JP (1989) Interplanetary dust particles collected in the stratosphere: observations of atmospheric heating and constraints on their interrelationships and sources. Icarus 82:146-166.

Signer P, Baur H, Derksen U, Etique P, Funk H, Horn P, Wieler R (1977) Helium, neon, and argon records of lunar soil evolution. Proc Lunar Sci Conf 8:3657-3683.

Takeda H, Nagaoka H, Yamaguchi A, Karouji Y, Yazawa Y (2015) Mineralogy of some evolved $L L$ chondrites with reference to asteroid materials and solar system evolution. Earth Planets Space 67:5. doi:10.1186/s40623-014-0167-x.

Taylor S, Lever JH, Harvey RP (1998) Accretion rate of cosmic spherules measured at the South Pole. Nature 392:899-903.

Thompson MS, Christoffersen R, Zega TJ, Keller LP (2014) Microchemical and structural evidence for space weathering in soils from asteroid Itokawa. Earth Planets Space 66:89.

Tomeoka K, Buseck PR (1988) Matrix mineralogy of the Orgueil Cl carbonaceous chondrite. Geochim Cosmochim Acta 52:1627-1640.

Toppani A, Libourel G, Engrand C, Maurette M (2001) Experimental simulation of atmospheric entry of micrometeorites. Meteoritics Planetary Sci 36:1377-1396.

Trappitsch R, Leya I (2013) Cosmogenic production rates and recoil loss effects in micrometeorites and interplanetary dust particles. Meteoritics Planetary Sci 48:195-210.

Trull TW, Kurz MD (1993) Experimental measurements of ${ }^{3} \mathrm{He}$ and ${ }^{4} \mathrm{He}$ mobility in olivine and clinopyroxene at magmatic temperatures. Geochim Cosmochim Acta 57:1313-1324.

Tsuchiyama A, Uesugi M, Matsushima T, Michikami T, Kadono T, Nakamura T, Uesugi K, Nakano T, Sandford SA, Noguchi R, Matsumoto T, Matsuno J, Nagano T, Imai Y, Takeuchi A, Suzuki Y, Ogami T, Katagiri J, Ebihara M, Ireland TR, Kitajima F, Nagao K, Naraoka H, Noguchi T, Okazaki R, Yurimoto H, Zolensky ME, Mukai T, Abe M, Yada T et al (2011) Three-dimensional structure of Hayabusa samples: Origin and evolution of Itokawa regolith. Science 333:1125-1128.

U. S. Standard Atmosphere (1976) U. S. Govt. Printing Office, Washington, DC.

Wang A, Kuebler KE, Jolliff BL, Haskin LA (2004) Raman spectroscopy of Fe-Ti-Croxides, case study: Martian meteorite EETA79001. Am Mineral 89:665-680.

Wieler R, Etique P, Singer P, Poupeau G (1980) Record of the solar corpuscular radiation in minerals from lunar soils: a comparative study of noble gases and tracks. Proc Lunar Sci Conf 11:1369-1393.

Wieler R, Etique P, Singer P, Poupeau G (1983) Decrease of the solar flare/solar wind flux ratio in the past several aeons deduced from solar neon and tracks in lunar soil plagioclase. J Geophys Res 88(S02):A713-A724. doi:10.1029/ JB088iS02p0A713.

Wieler R, Grimberg A, Heber VS (2007) Consequences of the non-existence of the "SEP" component for noble gas geo-and cosmochemistry. Chem Geol 244:382-390.

Wu TW, Kohlstedt DL (1988) Rutherford backscattering spectroscopy study of the kinetics of oxidation of (Mg, Fe) ${ }_{2} \mathrm{SiO}_{4}$. J Am Ceram Soc 71:540-545.

Yada T, Nakamura T, Noguchi T, Yano H, Terada K, Nakazawa T, Takaoka N, Kojima $H$ (2004) The global accretion rate of extraterrestrial materials in the last glacial period estimated from the abundance of micrometeorites in Antarctic glacier ice. Earth Planets Space 56:67-79.

Yurimoto H, Abe K, Abe M, Ebihara M, Fujimura A, Hashiguchi M, Hashizume K, Ireland TR, Itoh S, Katayama J, Kato C, Kawaguchi J, Kawasaki N, Kitajima F, Kobayashi S, Meike T, Mukai T, Nagao K, Nakamura T, Naraoka H, Noguchi T, Okazaki R, Park C, Sakamoto N, Seto Y, Takei M, Tsuchiyama A, Uesugi M, Wakaki S, Yada T et al (2011) Oxygen isotopic compositions of asteroidal materials returned from Itokawa by the Hayabusa mission. Science 333:11161119.

Zolensky ME, Zega TJ, Yano H, Wirick S, Westphal AJ, Weisberg MK, Weber I, Warren JL, Velbel MA, Tsuchiyama A et al (2006) Mineralogy and petrology of comet 81P/Wild 2 nucleus samples. Science 314:1735-1739.

\section{Submit your manuscript to a SpringerOpen ${ }^{\circ}$ journal and benefit from:}

- Convenient online submission

- Rigorous peer review

- Immediate publication on acceptance

- Open access: articles freely available online

- High visibility within the field

- Retaining the copyright to your article

Submit your next manuscript at springeropen.com 